\title{
LA SÍFILIS Y SU CARÁCTER ENDÉMICO EN LA CIUDAD DE MÉXICO
}

\author{
Lourdes Márquez Morfín \\ Escuela Nacional de Antropología e Historia
}

La sífilis [...] es una enfermedad virulenta, especial del hombre, nunca desarrollada espontáneamente sino transmitida por contagio o por herencia, la vemos atacar al niño como al viejo, al fuerte como al débil, al de un temperamento sanguíneo como al de uno linfático, al rico como al pobre.

Francisco de P. Leal, $1878 .{ }^{1}$

\section{LA SÍFILIS ENDÉMICA EN MÉXICO}

T a presente investigación parte de una óptica episteLmológica cuyo objetivo central radica en la identificación del carácter endémico de la sífilis entre los habitantes de la capital de México en especial durante el siglo XIX, con

Fecha de recepción: 20 de enero de 2014

Fecha de aceptación: 6 de mayo de 2014

${ }^{1}$ BMM. Clasificación: S-T, 1870, HIG (exp. 6). F.A.R. de Poincy, "Estudio Práctico sobre la sífilis infantil, hereditaria y adquirida", México, 1883, 52 pp. Orleans y París. Fue estudiante de los hospitales de Nueva 
lo cual pretendo desdibujar fronteras a partir de la construcción de ejes de investigación multidimensional y transdisciplinaria, mediante un acercamiento integral y holístico. ${ }^{2}$ Con esta finalidad diseñe una metodología basada en dos fuentes primarias de información; el estudio está fundamentado en documentos de archivo, con una extensa revisión y análisis de los más relevantes, procedentes de los hospitales, tratados médicos, prensa, reglamentos, publicaciones en La Gaceta Médica y el Boletín del Consejo Superior de Salubridad. Acudí a estudios específicos sobre la prostitución y la sífilis en el siglo xix y otros acerca de la salud pública, para entender el contexto social y sanitario de la época. Si bien el trabajo está centrado en los capitalinos, la presencia de la sífilis no se restringía a la ciudad de México, sino que estaba ampliamente diseminada en otras regiones del país. Para el análisis estadístico, tipificación y evaluación cuantitativa, acudí a una fuente primaria, no convencional entre los historiadores; corresponde a investigaciones osteopatológicas de varios cientos de esqueletos, originarios de los entierros realizados en el piso de iglesias, en cementerios de conventos

Orleans, París, Lyon, Wurzburgo, doctor en medicina por las facultades de Nueva Orleans, exmédico en este lugar y miembro de la Asociación de Beneficencia "Howard", Sociedad italiana "Tiro al Bersaglio", "Asociación Caritativa de los Bomberos", Sociedad italiana "Santo Bartolomeo", Asociación de Beneficencia "Vieja Portuguesa”. Presentó su tesis de examen profesional en México. Imprenta y Litografía Española. San Salvador el Seco Núm. 11, 1883.

${ }^{2}$ Los problemas de la relación salud sociedad promueven la interacción de la antropología física con otras ciencias, trascendiendo y sintetizando varios campos disciplinares, desdibujando sus fronteras a partir de la construcción de ejes de investigación multidimensionales, multidisciplinarios y transdisciplinarios, que son los que adopto. 
y hospitales, excavados por arqueólogos. Algunas de estas colecciones óseas fueron estudiadas mediante la metodología de la antropología física. ${ }^{3}$ En 1976 se extrajeron del piso de la nave de la Catedral metropolitana más de 2000 esqueletos de los siglos XVII al XIx. ${ }^{4}$ La investigación que yo realicé en 1979 de dichos materiales me permitió identificar varias decenas de casos de sífilis. Entre estos esqueletos se encontraba parte de la clase alta de la sociedad capitalina, lo que constituye un factor muy valioso para el estudio epidemiológico de este grupo social. ${ }^{5}$ Para el presente estudio, con el fin de evaluar la frecuencia de la sífilis en otros grupos socioétnicos, seleccioné otras dos colecciones esqueléticas: la serie del cementerio del Hospital Real de Indios (San José de los Naturales, con 325 esqueletos), que representa a la pobla-

${ }^{3}$ La metodología paleopatológica permite reconocer y diagnosticar la sífilis venérea, su distribución en el cuerpo y las partes más afectadas. Para la metodología véanse OrTner y Putschar, Identification of Paleopathological; SteInвock, Paleopathological Diagnosis; Boldsen, "Leprosy in the Early Medieval”, pp. 301-310; Aufdeheide, y Rodríguez-Martin, The Cambridge Encyclopedia.

${ }^{4}$ Márquez Morfín, "Disease and Society”, pp. 6-8; Márquez Morfín, Sociedad colonial y enfermedad. Desafortunadamente los esqueletos fueron extraídos con maquinaria pesada, lo que hizo que los huesos se mezclaran. Es así que se analizaron las unidades óseas por separado: 3042 fémures, 2207 tibias, 1801 peronés, 2554 húmeros, 2835 cúbitos, 2766 radios. Márquez y Meza, "La sífilis en la ciudad de México". Otras series proceden de obras de infraestructura urbana de la ciudad: restos óseos del Hospital de San Juan de Dios, de San José de los Naturales, del panteón de Santa Paula, del convento de Santa Isabel, de San Jerónimo y el de la Encarnación. El laboratorio de bioarqueología de la Escuela Nacional de Antropología e Historia cuenta con un acervo de 77 esqueletos recuperados del Hospital de San Juan de Dios, procedentes fundamentalmente del siglo XIX.

${ }^{5}$ Márquez, "Los parroquianos del Sagrario”, pp. 95-125. 
ción indígena, ${ }^{6}$ y los esqueletos del Hospital de San Juan de Dios (77 esqueletos y un osario), que durante un tiempo atendió a los enfermos de sífilis, donde suponemos acudió población mestiza, pero esencialmente gente de escasos recursos de distintas "calidades". Los resultados, análisis y discusión de estos dos tipos de fuentes descubren un escenario complejo, que revela a todos los sectores sociales afectados por la sífilis: indígenas, grupos desamparados, personas "respetables" con recursos económicos, mujeres públicas y sus clientes, soldados y niños con sífilis congénita; particularmente para los niños, como "grupo biosocial ignorado, o invisible", la información es escasa. ${ }^{8}$ Es así que la metodología empleada tiene un carácter integral, e identifica a la sífilis como problema endémico de salud pública y sus repercusiones. Las listas de enfermos que ingresaron al hospital de San Juan de Dios en 1844 y 1877 y de los fallecidos en 1891 contienen datos sobre lugar de origen, edad, sexo y causa de

${ }^{6}$ En su tesis de grado sobre condiciones de vida y salud, Oana del Castillo reportó varios casos de sífilis. Castillo, "Condiciones de vida". En otra tesis de licenciatura sobre la misma colección, Espinosa Solís "Sexualidad y sífilis", profundizó en el tema. El tamaño de la serie esquelética depende de los objetivos de cada investigación, de acuerdo a los criterios de selección. En los restos óseos del convento de San Jerónimo se identificó también un caso de sífilis congénita. Mansilla, "A case of congenital", pp. 187-195.

7 En la colección de esqueletos de niños del convento de Santa Isabel, estamos analizando diversos casos con huellas de sífilis congénita. Esta investigación se encuentra en curso, bajo mi responsabilidad, en el laboratorio de la Escuela Nacional de Antropología e Historia. Incorporamos en este texto algunos de los resultados de la investigación amplia sobre la sífilis que se encuentra en Márquez y Meza, "La sífilis en la ciudad de México".

${ }^{8}$ Márquez Morfín (ed.), Los niños, actores. 
muerte. La distribución por edad y sexo se compara con los resultados osteológicos de la serie esquelética explorada en dicho hospital, la cual coincide con los porcentajes obtenidos a partir del registro de mujeres públicas de la ciudad de México para 1865.

El artículo está estructurado a partir de la descripción del contexto social y demográfico de la ciudad, algunos antecedentes sobre la sífilis en México, su origen, etiología, características biológicas y el diagnóstico médico de la época. Expongo aspectos de salud pública relacionados con la sífilis y la vida urbana, las medidas sanitarias enfocadas al control y la vigilancia de las prostitutas. ${ }^{9}$ Las estadísticas de San Juan

9 Para México Ana María Carrillo describe la problemática de la época y las formas de control político mediante el control sexual. CARrILLO, “Control sexual”, pp. 65-77. Para Europa, el doctor Juan José Ramírez de Arellano, tomando en consideración los informes de diversas formas de control sanitario de la prostitución ejercido en Europa, menciona datos de Baviera, Inglaterra y Bélgica. Plantea que la estrategia más adecuada para disminuir el contagio por sífilis es mediante el registro sanitario de las mujeres públicas y las revisiones periódicas de su estado de salud, así como "el secuestro de las enfermas" en los hospitales especiales. Argumenta en contra de la prohibición o de la libertad total del ejercicio de la prostitución. Si bien el Reglamento sobre la prostitución y las labores de los inspectores sanitarios se establecieron en 1865, la aplicación y el funcionamiento no fueron adecuados. 30 años más tarde, en 1893, se describe que en todo el año hubo tan sólo 12758 reconocimientos y los divide entre el número de semanas del año, para mostrar que solo 210 son las mujeres que se vigilaron. Muestra así que se inscribió un reducido número de prostitutas, ya que la mayoría evadía la inspección. También se prohíbe el reconocimiento en las casas. De acuerdo con las estadísticas citadas por el doctor Ramírez, en 32 años sólo se inscribieron 5822 mujeres, "cifra en extremo pequeña, comparada con la real de mujeres que en tan largos años han vivido en México entregadas al desorden y al libertinaje”. Boletín del Consejo Superior de Salubridad, II: 4 (31 oct. 1896), pp. 89-90. 
de Dios para 1844 y 1877, como institución encargada de la atención de los enfermos de sífilis, constituyen un aspecto central. Las formas de contagio de la sífilis: por contacto sexual, durante el embarazo, el parto, el amamantamiento y la vacunación, así como los experimentos que algunos médicos hicieron para crear una vacuna contra la sífilis, son temas relevantes y me permitieron abordar la cuestión en las múltiples dimensiones emanadas de la documentación respectiva, en especial durante el siglo xIx.

\section{SÍFILIS EN LA CAPITAL}

La sífilis venérea, un tipo de treponematosis, es una de las enfermedades infecciosas crónicas y severas sin erradicar para la que no existe aún vacuna. Los estudios epidemiológicos mediante los cuales es posible conocer su frecuencia son difíciles de realizar por la carencia de registros y estadísticas médicas. ${ }^{10} \mathrm{El}$ debate sobre el origen geográfico y temporal de la sífilis venérea es muy amplio y todavía no hay una postura definitiva, pero recientes investigaciones integrales argumentan que no existen pruebas claras y contundentes en Europa antes del siglo xv. ${ }^{11}$ La controversia acerca de su

${ }^{10}$ Ricardo Cicero, dermatólogo mexicano de principios del siglo xx, menciona que si fuera posible tener estadísticas sobre los enfermos de sífilis quedaríamos horrorizados. Citado por CARRILlo, "Control sexual”, p. 65. ${ }^{11}$ Los estudios actuales plantean que el tipo de treponematosis más antiguo, la pinta, se identificó en África. Наскетт, Diagnostic. En este trabajo no discutiremos las diferentes teorías al respecto, pues el centro de la investigación es la sífilis en la ciudad de México en el siglo xIx. Para los interesados se pueden consultar obras generales sobre el tema. Los estudios más amplios y completos son: HARPer et al., "The Origin and Antiquity of Syphilis", pp. 99-133; НАскEтT, "On the origin of the human 
procedencia data de 1493, cuando adquiere carácter epidémico en Europa. Españoles, italianos, franceses entre otros, se negaban a aceptar "la denominación de origen" del padecimiento, de ahí que los españoles lo nombraran "mal gálico", o bien los franceses "mal napolitano". ${ }^{12}$ En México, así como en otras partes de América, la treponematosis ha sido registrada en restos prehispánicos. ${ }^{13}$ En la Nueva España tanto indios como españoles padecían sífilis. ${ }^{14}$ Se ha propuesto que

treponematoses”, pp. 7-41. Librado Vega, médico mexicano, culpa a Gonzalo Fernández de Oviedo de haber propagado la idea del origen americano del mal y argumenta sobre la historia y antigüedad de la sífilis recurriendo a diferentes escritos donde se menciona la presencia del padecimiento en Europa. VEGA, "Los accidentes secundarios".

12 VegA, "Los accidentes secundarios". Este autor hace un relato pormenorizado de las ideas en el siglo xvi acerca del origen de la sífilis: se le atribuía a abundantes lluvias, al comercio de hombres infectados de lepra con mujeres públicas, al envenenamiento del agua por parte de los españoles a los franceses, al suministro de carne humana adobada. En este trabajo existe una mención donde se afirma que "el gálico era endémico en las provincias de África, situadas en una y otra banda del Senegal”.

${ }^{13} \mathrm{La}$ treponematosis ocurre en cuatro enfermedades diferentes clínicamente y tiene una distribución geográfica que abarca zonas templadas y tropicales de todos los continentes. Las variantes son: pinta o mal del pinto, yaws (pian, frambesia), sífilis endémica o bejel (treponarid) y sífilis venérea. Desde el punto de vista evolutivo la más antigua es la pinta, con 15000 años, seguida del yaws que surgió hace 10000 ; la sífilis endémica se identifica alrededor de hace 7000 años y la más reciente es la venérea, con 3000 años. Estas tres últimas afectan el esqueleto, de ahí que se pueda reconocer su presencia en los estudios osteopatológicos realizados a partir de series óseas. Se han reportado casos de yaws en el periodo prehispánico. Para Colombia el registro de ejemplares con huellas de sífilis venérea es amplia. НАСКETT, "On the origin of the human treponematoses", pp. 7-41; НАCKETT, “An introduction to diagnostic", pp. 368, 229-241; Cook y Powell, "Treponematosis”; Rodríguez Cuenca, Las enfermedades.

${ }^{14}$ Muriel, Hospitales de la Nueva España, pp. 158-159. 
el contagio probablemente se debió a un cambio en la espiroqueta causante de la enfermedad, o bien a que alguno de los grupos biológicos (español) no había tenido contacto previo con esa variante, por lo cual se diseminó a lo largo del país. Antes de su identificación como complicación de índole venérea, la sífilis era tratada como cualquier enfermedad contagiosa. No fue sino hasta su reconocimiento como infección adquirida por medio de las relaciones sexuales que los preceptos morales estimularon un sentido de vergüenza y pavor ante la conciencia propia, de familiares, amigos o del médico. En el imaginario social, matizado por la corriente higienista, era considerada como mayoritaria entre los pobres, marginados, gente promiscua, sucia, de los léperos y prostitutas en general. Durante el siglo XIX, en Francia existía la preocupación constante de las enfermedades venéreas, así como un reconocimiento de su difusión en todos los niveles sociales. Este periodo ha sido identificado como el de reglamentación, mediante el registro e inspección regular de prostitutas para controlar el mal; sin embargo, a pesar del reconocimiento de la gran cantidad de mujeres respetables, de clase media, enfermas de sífilis, ese sector social no recibía el tratamiento adecuado, si es que los médicos decidían atenderlas, por temor a evidenciar lo extendido de la infección. En México se presentaba la misma situación: el temor al contagio por medios tan "bajos" provocaba pena, miedo, se conservaba en la opacidad, en la secrecía. Los médicos privados encargados de la gente "decente": esposas, madres, hijas, o cualquier miembro "respetable" de la sociedad, enferma de sífilis, consideraban poco adecuado dar un diagnóstico. Carrillo plantea en su estudio sobre el control sexual para inicios del siglo xx que "enfermaban pobres y ricos, hombres y muje- 
res, adultos y niños"; ${ }^{15}$ también menciona el reclamo de los médicos ante la falta de estadísticas confiables sobre un grave problema colectivo de salud.

El México independiente es reconocido por el caos político, los importantes cambios sociales y los continuos movimientos armados: la guerra de independencia, la invasión estadounidense, la guerra con Francia, además de la inestabilidad y fragilidad política debidas a sublevaciones, levantamientos y otros conflictos. ${ }^{16}$ Éste es un escenario totalmente negativo para atender los problemas de salud de una población pobre, sin preparación y expuesta a todo tipo de vaivenes. El contexto de enfermedad salud en esta época no difería del de los siglos anteriores; las epidemias, tan conocidas por los mexicanos, entre ellas la de tifo (1813) y la de viruela, seguían haciendo estragos; el arribo de nuevas infecciones, tales como el cólera, en 1833, 1850, 1860 y 1870 y la influenza en 1847 vendrían a empeorar el panorama de salud pública. Las epidemias reconocidas como causantes de grandes mortandades eran la preocupación fundamental de las autoridades sanitarias, mientras la sífilis no era identificada como enfermedad endémica y permanecía en la secrecía. ${ }^{17}$ Las enfermedades venéreas, dado su carácter de transmisión sexual, son mantenidas en secreto a causa de la vergüenza, el

${ }^{15}$ Carrillo, "Economía, política”, pp. 67-87.

16 Rodríguez Kuri (coord.), Historia política; Pérez Toledo, “Formas de gobierno", pp. 221-286.

17 La bibliografía sobre epidemias es muy amplia, en particular para la ciudad de México. Pueden consultarse Florescano y Malvido, Ensayos; Márquez Morfín, "El cólera en México”, pp. 349-362; Márquez Morfín, La desigualdad ante la muerte; Molina Del Villar, La Nueva España; Molina del Villar et al., El miedo a morir; Lugo y Malvido, "Las epidemias". 
escarnio social y cultural asociado, al igual que ocurre hoy en día, para mucha gente, con el síndrome de inmunodeficiencia adquirida (SIDA).

En el contexto demográfico de la capital sabemos que a finales del siglo xviı, según el censo de Revillagigedo, la ciudad tenía 112932 habitantes y 20 años después ascendió a 168 846; para 1838 la población aumentó a 205430 personas, ${ }^{18}$ con un crecimiento natural modesto, estimulado por la inmigración constante a la ciudad, en particular de mujeres y hombres jóvenes, quienes llegaban continuamente en busca de trabajo a lo largo del siglo. 30 años más tarde las cifras permanecen iguales (200000) y para 1894 "rondaban los 350000". Como Fausta Gantús indica, el incremento "puede estimarse entre $53.2 \%$ u $87.4 \%$, si consideramos que el aumento de personas ascendió de 225000 a 344721 , según el censo, o 421836 según Estadísticas Históricas de México". ${ }^{19}$ Algunos autores caracterizan la ciudad con un estancamiento demográfico por lo menos hasta 1860, a pesar de la alta inmigración, estimada entre 35 y 45\%, para 1811 y 1842. De acuerdo al padrón de 1882 los capitalinos no rebasaban los $193000,{ }^{20}$ cifra incluso inferior a la reportada en 1838. Las causas de la inmigración estaban asociadas con el conflicto armado, así como con factores económicos. Sólo $30 \%$ de la población total tenía acceso a una ocupación más

${ }^{18}$ Los cálculos de población son siempre aproximaciones cuantitativas. Las discrepancias entre los autores son comunes. Márquez Morfín, "Población y sociedad".

${ }^{19}$ Gantús, "La traza del poder político", p. 296. Las cifras difieren dependiendo del tipo de fuente; véase la tabla 2, p. 297.

20 Pérez Toledo, "Formas de gobierno", p. 225. Pérez Toledo y Klein, Población y estructura social. 
o menos estable, $50 \%$ de las personas en edad laboral carecían de trabajo fijo. ${ }^{21}$ La mayoría estaba empleada en la fabricación de productos artesanales, el pequeño comercio y los servicios, en particular el doméstico. ${ }^{22}$ La capital fue abrigo de los grupos más desvalidos en las épocas de violencia política, de guerras, e invasiones; éstos engrosaban las filas de desempleados, vagabundos y "malentretenidos". También encontramos enfermos buscando auxilio en los hospitales, donde en no pocas ocasiones hallaban un lugar sólo para morir, o bien, en momentos de crisis, se refugiaban pidiendo comida y asilo. De acuerdo con Manuel Miño "[...] hacia finales de la década de 1820 el vagabundo o el comerciante, vendedor 'informal' pululará por las diversas calles de la ciudad vendiendo en banquetas y esquinas, con sus mesas, puestos con dulces, vendimias, 'comistrajos', tripas o azadura $[\ldots]$ ". ;3 la ciudad sufría un cambio de productora artesanal a comerciante. Para finales del siglo xIx la población capitalina era urbana, la mayoría jóvenes, $74 \%$ entre los 18 y 50 años, con una clase media en crecimiento, parte profesionales, otros comerciantes y amplios sectores populares de empleados en fábricas y talleres, así como en servicios. ${ }^{24}$ Éste es el escenario donde una enfermedad como la sífilis adquiere un carácter endémico, ya que el grupo de riesgo son precisamente los jóvenes.

${ }^{21}$ Márquez Morfín, La desigualdad ante la muerte; Moreno Toscano y Aguirre, "Migraciones".

22 Pérez Toledo, "Formas de gobierno", p. 225.

${ }_{23}$ Miño, "La ciudad de México", pp. 460-471.

${ }^{24}$ Gantús, “La traza del poder político”, p. 296, n. 17. 
LA SÍFILIS Y SU ATENCIÓN HOSPITALARIA

En el siglo xvi, dentro de la traza urbana de la capital había dos hospitales: el Real de Indios y el de Nuestra Señora de la Concepción. El Real, dedicado a la atención del grupo indígena, y el del Marqués, de acuerdo con Muriel, "de capacidad reducida, no tenía sitio para albergar separadamente a los bubosos o sifilíticos, enfermedad cuyo contagio era visto con verdadero pavor". ${ }^{25}$ Juan de Zumárraga fundó en 1539 el Hospital del Amor de Dios para tratar las bubas, con capacidad de 40 camas. Este recinto tenía salas para hombres y mujeres donde proporcionaban tratamiento de unciones mercuriales cotidianas para el gálico. El cuidado a enfermos fue aumentando a medida que había más contagiados y para el siglo XVIII podían asistir hasta 150 y según la necesidad ampliarse a 200. En 1781 fueron atendidos 4500 enfermos en el año, a razón de 150 camas diarias. Los servicios clínicos estaban a cargo de un médico, un cirujano mayor, cirujano segundo, enfermero mayor de hombres, enfermero segundo y tres enfermeros ayudantes, dos untadores y además de un barbero y un jarabero para las mujeres una enfermera mayor, tres ayudantas y dos untadoras. En 1786 el Hospital del Amor de Dios fue suprimido y sus recursos económicos trasladados al Hospital de San Andrés. Los enfermos de gálico fueron enviados a San Andrés para su atención. ${ }^{26}$ Los servicios hospitalarios iniciaron un cambio en la concepción de los enfermos y su atención desde mediados del siglo XviII, hacia un enfoque tendente al mejoramiento de los servicios

25 Muriel, Hospitales de la Nueva España, pp. 159-160.

26 Martínez Barbosa, “El Hospital de San Andrés”, p. 499. 
clínicos y una ciencia médica, dejando atrás la mística de la caridad de las órdenes religiosas, sustituida por el interés en la salud pública. ${ }^{27}$

Para atender al número creciente de enfermos fueron erigidos otros hospitales bajo la responsabilidad de la orden de San Juan. ${ }^{28}$ En estos lugares los enfermos eran recluidos y mantenidos hasta su curación, lo que raramente sucedía, dado las características de la enfermedad y la falta de un tratamiento adecuado, convirtiéndose en verdaderas prisiones donde la vigilancia era permanente. ${ }^{29}$ Para el siglo xix la sífilis ya era reconocida en Francia y México como común y de alta frecuencia; su carácter endémico era patente entre los médicos capitalinos. ${ }^{30}$ Los hospitales especializados eran San Juan

${ }^{27}$ Carrillo, "Economía, política”, pp. 67-87; Muriel, "Los hospitales en el siglo ilustrado”, p. 491.

${ }^{28}$ La sífilis tuvo una presencia significativa poco tiempo después del arribo de los españoles. Muriel, Hospitales de la Nueva España. Los documentos de diversa índole describen la presencia de la enfermedad. AGN, GD 61, Instituciones Coloniales, Inquisición, vol. 83, exp. 9, f. 2 (1577). Para el siglo XviI tenemos otro ejemplo: se reporta una esclava comprada en 1675 con diferentes achaques, todos de bubas. AGN, Colonial, Instituciones Coloniales, Tribunal Superior de Justicia de la Cindad de México, Alcaldes del Crimen (Juzgado de Provincia), Procesos Civiles, c. 8B, exp. 43 (1675), f. 7.

29 Reglamento aprobado por el Ayuntamiento Constitucional de México para el servicio médico, administrativo y hospitalario del hospital de mujeres venéreas, conocido con el nombre de "San Juan de Dios", México 1873. AGN, Ayuntamiento, Hospitales, Hospital San Juan de Dios, vol. 2305, exp. 92 (1873).

${ }^{30}$ El doctor Ramírez menciona: "Desgraciadamente hasta ahora, y por causas múltiples [...]. La sífilis es demasiado común entre nosotros, y raro es el hombre que durante su vida no paga algún contingente a la satisfacción de sus placeres", Boletin del Consejo Superior de Salubridad, II: 4 (31 oct. 1896), pp. 89-90, 93. 
de Dios y San Andrés, considerados hospitales general. ${ }^{31}$ Las personas que acudían a ellos eran las de menores recursos y mayor susceptibilidad, dadas sus precarias condiciones de vida. El Hospital de San Juan de Dios inició sus funciones en 1605, en lo que fue el Hospital de Nuestra Señora de los Desamparados. A mediados del siglo XviI se construyeron dos grandes enfermerías, una baja para mujeres y otra alta para hombres, con 50 camas cada una. Para 1734 hubo otras ampliaciones y en 1815 el hospital estaba en buenas condiciones; mantenía las 100 camas, fabricadas de tablas y travesaños de fierro, pintadas de verde, con colchones, sábanas de brin y cobijas de lana y almohadas. Las paredes de las enfermerías tenían lambrín de azulejos por cuestiones de higiene. Los ingresos en 1813-1815 ascendían a 48604 pesos, sin embargo, los gastos eran superiores (50180 pesos). El hospital prestaba servicio a todo tipo de personas, incluso militares, y a cualquier clase de enfermos excepto locos, leprosos y sifilíticos, ${ }^{32}$ ya que había hospitales especializados para estas dolencias; sin embargo, estos últimos fueron integrados a San Juan de Dios cuando se trasladó, años más tarde, a los enfermos del pabellón de gálico de San Andrés. En 1820, con la Constitución de Cádiz, las órdenes hospitalarias fueron suspendidas y el edificio pasó al ayuntamiento colonial y posteriormente al gobierno mexicano. ${ }^{33}$ Las personas de escasos recursos que no podía pagar un médico para visita domiciliaria acudían al hospital, donde eran revisados y admitidos para su tratamiento. La vigilancia a los enfer-

31 Martínez Barbosa, “El Hospital de San Andrés”, pp. 499-509.

32 Muriel, Los Hospitales de la Nueva España, pp. 29-33.

33 Muriel, Los Hospitales de la Nueva España, pp. 34-38. 
mos era constante, pues las epidemias continuaban asolando a la capital, además de los padecimientos cotidianos. Las nuevas autoridades de los hospitales enfrentaban dificultades por la falta de recursos dado el aumento de infectados. Para 1841, en la ciudad de México quedó establecido el Consejo Superior de Salubridad, cuya labor consistía en vigilar la correcta práctica del ejercicio de la medicina y farmacia, llevar a cabo acciones sanitarias y realizar estudios sobre diversas epidemias. ${ }^{34}$ Los cambios más significativos en salubridad, relativos a las enfermedades venéreas, ocurrieron en la segunda mitad de ese siglo, ${ }^{35}$ bajo la influencia de la "reglamentación" en la medicina francesa, ${ }^{36}$ enfocada al control de las prostitutas mediante su registro y examen médico regular. Dicho modelo fue aplicado en México bajo la supervisión del Consejo Superior de Salubridad, conformado por 22 médicos, 10 de los cuales eran franceses. A fines del siglo las labores del Consejo estaban a cargo de 23 comisiones, entre ellas la de epidemiología. ${ }^{37}$ Los conflictos acerca del

\footnotetext{
${ }^{34}$ Boletín del Consejo Superior de Salubridad, II: 2 (1896).

35 Carrillo, "Economía, política", pp. 67-87.
}

${ }^{36} \mathrm{El}$ nacimiento de la salud pública moderna se dió a fines del siglo xIx. Carrillo, "Economía, política," pp. 67-87. Los médicos sifilógrafos de mayor renombre fueron Philippe Ricord y su alumno Alfred Fournier. Ricord fue uno de los médicos más destacados en el hospital de enfermedades venéreas de París (Hopital du Midi). Es reconocido por sus investigaciones en torno a la identificación de la etiología de la sífilis y sus diferencias con la gonorrea. Durante largo tiempo sostuvo que la sífilis únicamente era contagiosa en su etapa primaria. Posteriormente se vio obligado a aceptar que en el estadio secundario también es posible contraer la enfermedad. BAILEY, "Obituary".

${ }^{37} 1^{\text {a }}$ Comisión el Sr. N.R. Arellano y $2^{\text {a }}$ Sr. A. Reyes encargado del Servicio de desinfección, $3^{\text {a }}$ Sr. J. J. R. de Arellano. Suplentes: Sres. Eduardo Liceaga y L.E. Ruiz. De Inspección Sanitaria el Sr. Francisco López 
cuidado de los pacientes pobres llevaban a los encargados de hospitales a rechazar su ingreso por falta de recursos y utilizar este argumento para pedir aumento al presupuesto. Sobre la admisión de internos en San Juan de Dios hay datos para 1772-1774, cuando recibieron a 5927 personas; 3508 hombres, de los cuales fallecieron 30, y 1419 mujeres, de las que murieron 275 , lo que muestra mayor mortalidad femenina. El promedio anual de enfermos en la segunda mitad del siglo XviII era de 3923 y se "encamaban" diariamente alrededor de 150 a 200 personas, que estaban al cuidado de 50 religiosos y novicios. Veinte años después había dos frailes, ocho criados, dos médicos, 44 enfermos y 56 enfermas. ${ }^{38}$ En 1821 el regidor Xavier de Heras estaba intranquilo por el incremento de internos en el Hospital de San Juan de Dios a su cargo. Cuando recibió el hospital había 45 enfermos y en julio de ese año llegaban a $200 .{ }^{39}$ En el registro

y Eduardo Liceaga. La Comisión de Epidemiología ordena a los inspectores sanitarios visiten a las personas atacadas de enfermedades infecto contagiosas, en el mismo día en que reciben aviso del médico que las asiste; dan aviso por medio de tarjetas postales según modelo especial. El inspector debe cerciorarse de la situación del enfermo y debe dejar las instrucciones convenientes para su aislamiento, en la misma habitación si es posible, para evitar el contagio de otras personas. La Comisión debe anotar la ubicación de la casa, sexo y edad del enfermo, días que lleva de enfermedad, causa probable de ella, lugar donde la contrajo, y si es preciso trasladarlo al hospital, si es imposible el aislamiento. Los datos relativos a enfermos infecciosos deben consignarse en libros especiales que lleva la Secretaría. Boletín del Consejo Superior de Salubridad, II: 2 (31 ago. 1896). AHSSA.

${ }_{38}$ Muriel, los Hospitales de la Nueva España, pp. 34-38.

39 AHDF, Beneficencia Pública, Ayuntamiento, Hospitales, Hospital San Juan de Dios, vol. 2304, exp. 14 (1821). Los hospitales eran de especialidad. El de San Andrés era un hospital general con un pabellón de gálico. 
Gráfica 1

DISTRIBUCIÓN DE EDAD. REGISTRO DE INTERNOS

DEL HOSPITAL DE SAN JUAN DE DIOS PARA 1844

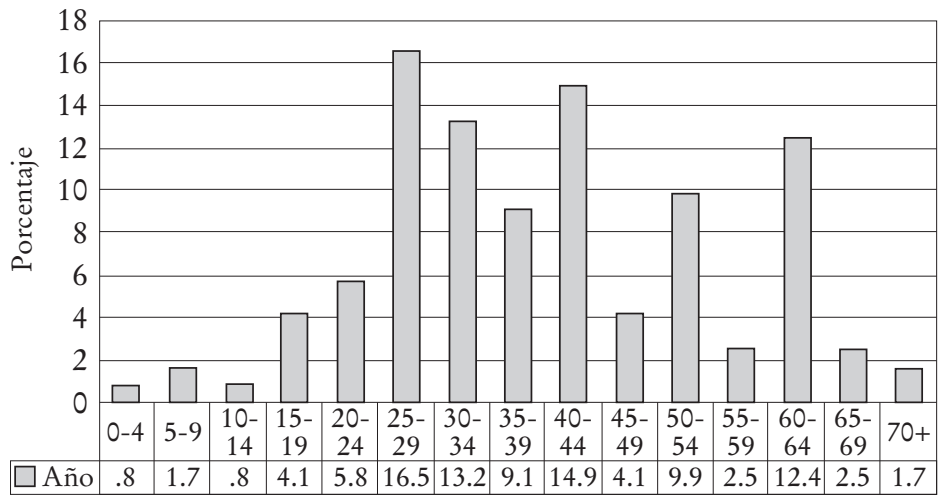

Fuente: BP, EH, leg., 2 (1844).

de 1844, cuando el hospital estaba a cargo de las hermanas de la Caridad; encontramos 121 internos, en su mayoría adultos: hombres y mujeres en porcentajes similares, entre los 20 y 60 años; tan sólo $7.4 \%$ eran menores de 20 años (gráfica 1). La mayoría padecía enfermedades respiratorias e infecciones gastrointestinales (52\%) y el resto estaba distribuido entre las denominadas "fiebres”, la hidropesía y un abanico de padecimientos, incluyendo los de transmisión sexual, aunque insignificantes frente a las dos primeras. ${ }^{40}$

Este patrón es común en poblaciones preindustriales e incluso el perfil epidemiológico de 1877 no difiere, pues esas infecciones son la principal causa de muerte; la cifra de enfermos registrados aumentó a 806: 432 hombres y 374 mujeres. La comparación de 1844 y 1877 en los fallecimientos por

${ }^{40}$ AHDF, Beneficencia Pública, EH, leg. 6, exp. 25. Ayuntamiento, Hospitales, Hospital San Juan de Dios, vol. 2305, exp. 43 (1868). 
enfermedad muestra las diferencias, en especial la viruela, enfermedades del hígado y venéreas sin datos (cuadro 1).

\section{Cuadro 1}

DISTRIBUCIÓN PORCENTUAL DE FALLECIMIENTOS POR ENFERMEDAD. HOSPITAL DE SAN JUAN DE DIOS (1844 Y 1877)

\begin{tabular}{cccc}
\hline 1844 & \multicolumn{2}{c}{1877} \\
\hline Enfermedad & $\%$ & Enfermedad & $\%$ \\
Respiratorias & 27 & Respiratorias & 21.7 \\
Gastrointestinales & 25 & Gastrointestinales & 28.4 \\
Fiebres & 8 & - & - \\
Otras & 40 & Otras & 29 \\
- & - & Viruela & 14.52 \\
- & - & Hígado & 5.58 \\
& - & Venéreas & - \\
\hline
\end{tabular}

Fuente: AHSSA, Salubridad Pública, Estadística, c. 3, exp. 3 (1844); c. 10 , exp. 22 (1877).

El incremento se debe fundamentalmente, como mencionamos antes, al traslado de los enfermos del pabellón del gálico del Hospital de San Andrés en $1868 .{ }^{41}$ Dos años atrás el Consejo de Beneficencia había decidido destinar San Juan de Dios a la curación de enfermas sifilíticas, ${ }^{42}$ pero no fue exclusivo para mujeres sino hasta años posteriores. ${ }^{43}$ En 1871, el gobernador del Distrito estableció la Inspección Sanitaria en dicho hospital, a causa del Reglamento sobre prostitución y se cons-

${ }^{41}$ AHDF, Ayuntamiento, Hospitales, Hospital San Juan de Dios, vol. 2305, exp. 43 (1868).

42 AHDF, Ayuntamiento, Hospitales, Hospital de San Juan de Dios, vol. 421, exp. 208 (1866).

43 AHDF, Ayuntamiento, Gobierno del D.F., Beneficencia, Consejo General, vol. 421, exp. 208 (1866). 
truyó una entrada en la parte trasera del edificio. ${ }^{44}$ La atención no era gratuita para todos. En 1872, el Consejo de Beneficencia, consciente de las implicaciones sobre la libertad individual que tenía recluir en el hospital a las prostitutas enfermas, considera importante revisar el diagnóstico y que los médicos de la Inspección Sanitaria indiquen a las mujeres su enfermedad. El Consejo estaría encargado de hacer la confronta y declara que:

Un hospital para mujeres sifilíticas es un ramo de la beneficencia pública, sin importar que sus desgraciadas moradoras hayan contraído la sífilis accidentalmente o por la prostitución, pues la beneficencia pública no se detiene en investigar las causas de una desgracia sino que se concreta a remediarla. ${ }^{45}$

En 1874, a las prostitutas remitidas por el inspector de Sanidad se les exigía pagar por los servicios, ya que de otro modo los cuatro médicos de la Inspección preferían atender a su clientela privada, en lugar de asistir a las 144 enfermas. Los cambios políticos ocurridos en esa época determinaron que San Juan de Dios cambiara su designación a "Hospital Morelos” en marzo de 1875 y las salas ya no llevarían nombre [...] "alguno de Santo, sino el número de orden". ${ }^{46}$ Para 1880 alojaba 140 mujeres; la más joven tenía sólo 13 años. ${ }^{47}$ Durante el porfiriato, el registro de 1891 refleja las transfor-

${ }_{44}$ AHDF, Ayuntamiento, Hospitales, Hospital San Juan de Dios, vol. 2305, exp. 66 (1871), 24 de octubre.

45 AHDF, Ayuntamiento, Hospitales, Hospital San Juan de Dios, vol. 2305, exp. 66 (1871), 24 de octubre.

46 AHDF, Ayuntamiento, Hospitales, Hospital San Juan de Dios, vol. 2305, exp. 117 (1875).

${ }^{47}$ El edificio pasó a ser hospital de enfermedades contagiosas a cargo de las Hermanas de la Caridad de 1845 a 1874, luego al Ayuntamiento y finalmente a la Junta de Beneficencia. 
maciones ocurridas años atrás, durante el Segundo Imperio, en la reglamentación del hospital. ${ }^{48}$ Los datos consignan 328 mujeres contagiadas de enfermedades venéreas. En los libros fue anotado el lugar de origen: la mayoría (41.6\%) del Distrito Federal, 10\% del Estado de México y cifra igual para Hidalgo; Puebla y Guanajuato alrededor de 8\% y el resto en los otros estados; había dos extranjeras procedentes de España. ${ }^{49}$ Los reportes de inmigrantes a la capital, originarios de diversas ciudades como Pachuca, Guanajuato, Irapuato, entre otras, son constantes. La distribución de edades de fallecidos en 1891 difiere de la de edades de 1844, cuando ingresaban con diversos padecimientos hombres y mujeres de todas las edades, muchos de ellos adultos mayores, pero mantiene el perfil del registro de mujeres públicas; la mayoría eran jóvenes de entre 15 y 25 años (gráfica 2). ${ }^{50}$

48 De acuerdo con CARrillo, “Economía, política”, pp. 68-69. En 1882 el Consejo Superior de Salubridad propuso la constitución de un Consejo Nacional de Salubridad Pública con facultades ejecutivas, para concentrar

[...] las estadísticas de morbilidad y mortalidad y fungir como un cuerpo consultivo general en materia de salubridad, encargarse de todo lo relativo a la policía sanitaria marítima, convocar a congresos nacionales de higiene y formar, con la participación de todos los estados, la legislación sanitaria de la república. Aunque este dictamen no pudo ponerse en práctica de manera inmediata, fue fundamental. Por un lado, porque delineó la forma en que el Estado porfirista se organizaría más tarde, estructural e ideológicamente, para enfrentar los problemas colectivos de salud.

El Reglamento del Hospital Morelos, de acuerdo a las disposiciones generales de 1928 establecía: "El Hospital Morelos está destinado para el aislamiento del seno de la Sociedad de las prostitutas que sean remitidas por la inspección de Sanidad en calidad de detenidas", Salubridad Pública, Servicio Jurídico, c. 15, exp. 1 (1928).

49 AHDF, Beneficencia Pública, EH, leg. 2, exp. 23.

50 AHDF, Beneficencia Pública, EH, leg. 2, exp. 23. 


\section{Gráfica 2}

DISTRIBUCIÓN DE EDAD EN MUJERES.

REGISTRO DE INGRESOS (1844 Y 1891),

HOSPITAL DE SAN JUAN DE DIOS

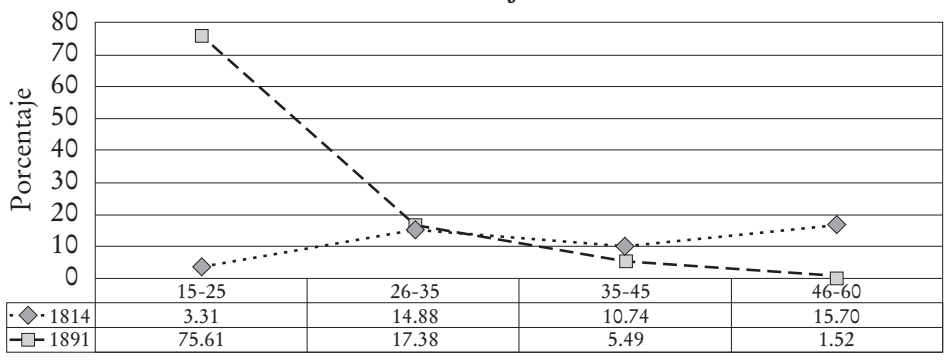

Fuente: BP, EH, leg. 2, e. 23 (1981) Hospital de Morelos.

TRAS LAS HUELLAS DE LOS “SIFILÍTICOS”

Como mencionamos al inicio, podemos obtener información sobre la sífilis a partir de las evidencias en sus esqueletos. Basados en esos resultados hicimos cálculos sobre la frecuencia de la sífilis en distintos grupos sociales de la ciudad de México, como una fuente invaluable de datos. Las investigaciones con base en los restos óseos identifican las marcas relacionadas con la sífilis para deducir su distribución entre hombres, mujeres y por grupos de edad. Se examinan las huellas registradas en el esqueleto, su localización y grado de severidad. El reconocimiento de la expansión del padecimiento por medio de los individuos mismos de esa época revela quiénes padecieron esta enfermedad: españoles, mestizos e indígenas, hombres, mujeres y niños. En síntesis, integramos información histórica y biológica, tanto cuantitativa como cualitativa, para indagar el efecto epidemiológico de la sífilis en los habitantes de la ciudad. 
La serie principal corresponde al Hospital de San Juan de Dios, designado en 1868 para recluir a enfermos de sífilis, gonorrea y otros padecimientos venéreos. Los enfermos recibidos en el hospital seguían el tratamiento, en ocasiones eran dados de alta y otras veces morían. Si esto ocurría se daba aviso a sus parientes y si nadie reclamaba el cuerpo, podía ser enviado a la Escuela de Medicina, o bien se le inhumaba en el cementerio de dicho hospital. ${ }^{51}$ De ahí que fue posible evaluar 77 esqueletos procedentes de este lugar ${ }^{52}$ e identificar $12 \%$ de los ellos con huellas severas de sífilis en el estadio terciario del padecimiento (figura 1).

Figura 1

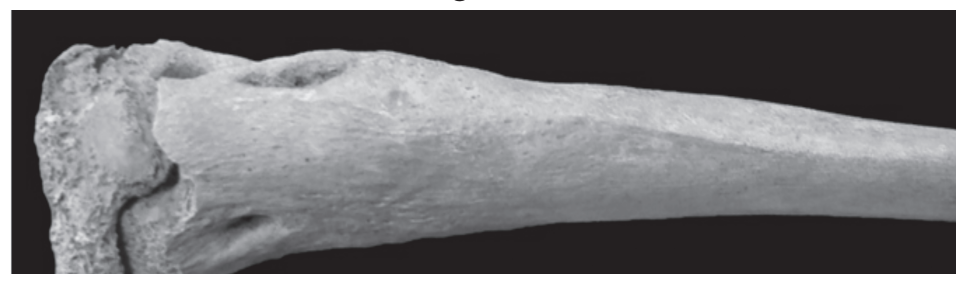

Huellas de sífilis en tibia derecha de un individuo femenino de entre $15 \mathrm{y}$ 18 años de edad. Serie esquelética del Hospital de San Juan de Dios.

$\mathrm{Al}$ respecto cabe mencionar que sólo $30 \%$ de los enfermos sifilíticos desarrollan este estadio, que es el identificado en los

51 “Cuando una enferma moría el médico administrador tenía que avisar a los deudos y dar parte al Registro Civil, no se podía sacar el cadáver sin antes presentar la boleta del Registro Civil. Si el cadáver no era reclamado se podía mandar a la Escuela de Medicina, o proceder al entierro de oficio.” AHDF, Ayuntamiento, Hospitales, Hospital de San Juan de Dios, vol. 2305, exp. 92, 1873.

${ }^{52}$ El estudio osteopatólogico está autorizado para publicación en la revista Cuicuilco. Márquez y Meza, "La sífilis en la ciudad de México". 
huesos, ${ }^{53}$ lo cual significa que existen esqueletos, sin evidencias óseas, de quienes murieron a causa del padecimiento, o bien por otro motivo. La distribución por sexo muestra porcentajes similares entre hombres y mujeres, y por grupo de edad; $69 \%$ se encontraron entre los 20 y 35 años (gráfica 3). Esta distribución se explica por sí misma, ya que los jóvenes y adultos en estas edades constituyen la población de riesgo para contraer enfermedades de transmisión sexual, como es la sífilis. También pueden estar representadas las prostitutas y los enfermos de gálico del Hospital de San Andrés. ${ }^{54}$ Los datos obtenidos del Hospital de San Juan de Dios descubren el impacto de la enfermedad en los sectores vulnerables de la sociedad capitalina: gente de escasos recursos, desempleados, pobres, desamparados, prostitutas y soldados.

\section{Gráfica 3}

DISTRIBUCIÓN POR GRUPOS DE EDAD.

SERIE ESQUELÉTICA DE SAN JUAN DE DIOS, SIGLO XIX

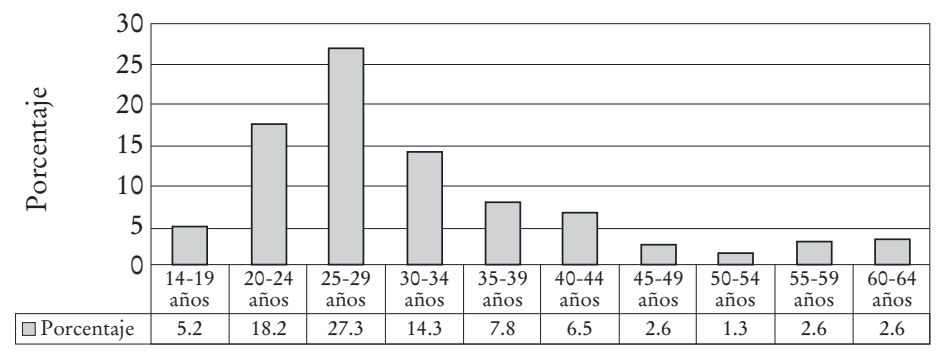

Fuente: Márquez y Meza, 2013.

53 Steinbock, Paleopathological Diagnosis; Наскетt, Diagnostic.

${ }^{54}$ AGN, Indiferente Virreinal, c. 5597, exp. 121, 1773, c. 2969, exp. 002, año 1797; c. 3258, exp. 18, hospitales, 1792. 
Pero me pregunto cuál era la situación en otros sectores sociales que no fueron atendidos en este hospital. Los indígenas recurrían al Hospital Real de los Naturales. En el estudio de 406 esqueletos de este sitio, 53 tenían modificaciones en los huesos relacionadas con la sífilis $(13 \%)$. La distribución por edad es similar a la del Hospital de San Juan de Dios, ya que los jóvenes de entre 25 y 35 fueron los más aquejados, con $64.2 \%{ }^{55}$ (gráfica 3). Es evidente que la población indígena de la capital no escapó a los embates del contagio. De acuerdo con Pilar Gonzalbo, en los barrios de indios que rodeaban la ciudad se notaba una creciente promiscuidad y pérdida de los controles de la comunidad. ${ }^{56}$ De ahí que no sea de extrañar el ingreso de enfermos sifilíticos al Hospital de San José de los Naturales, confirmado por el número de personas con afecciones óseas. ${ }^{57}$

La gente "honesta, decente, respetable" también contrajo sífilis, de acuerdo con el estudio de los esqueletos de la parroquia del Sagrario Metropolitano. ¿Quiénes eran los feligreses del Sagrario Metropolitano? Según el padrón de 1777, aunque incompleto, ascendían a 24345. Esta parroquia era bastante populosa, en ella vivían familias de diverso origen étnico, con un predominio español (71\%), con estatus social y económico diferente. Allí coexistían las gentes más acaudaladas de la capital; sin embargo, la mayoría de los feligreses eran de recursos modestos. ${ }^{58}$ En el padrón de 1811, 40 años después, en los

\footnotetext{
${ }^{55}$ Espinosa Solís, "Sexualidad y sífilis".

${ }^{56}$ Gonzalbo Aizpuru, Familia y orden colonial, p. 182.

57 Castillo, "Condiciones de vida y salud"; Márquez y Meza, "La sífilis en la ciudad de México".

${ }^{58}$ Existen diferencias en los porcentajes si la base son los individuos empadronados como españoles o el jefe de familia, por lo que correspon-
} 
cuarteles - 1, 5, 9 11, 13 y 14- de la misma parroquía, calculé aproximadamente 47000 personas. La composición étnica fue $63-74 \%$ registrados como españoles, $12-19 \%$ de indios y el resto de otras calidades, cifras similares a las de $1777 . .^{59}$

Los enfermos de sífilis de la capital atendidos de manera privada en su domicilio son un sector difícil de contabilizar por la falta de estadísticas. La presencia de la sífilis terciaria entre estas personas la obtuvimos del estudio de los esqueletos de la parroquia del Sagrario Metropolitano (3042 fémures, 2207 tibias, 1801 peronés, 2554 húmeros, 2835 cúbitos, 2766 radios), donde identificamos un porcentaje de 2.4 de casos severos ${ }^{60} \mathrm{Si}$ comparamos los resultados de San Juan de Dios, representan el doble $(5.6 \%)$ de este tipo de casos, similares a las cifras estimadas de los restos de Hospital de Indios; los cálculos generales dejan ver la mayor significancia del padecimiento entre la población indígena y por supuesto en los restos del Hospital de San Juan de Dios, donde fueron atendidos este tipo de enfermos. ${ }^{61}$ ¿Qué conclusiones puedo obtener de estas estimaciones? Consideremos primero las características epidemiológicas: sólo un tercio de los enfermos con

de a tres de los cuatro ramos de la parroquia. Gonzalbo Aizpuru, Familia y orden colonial, pp. 273-283.

59 Márquez Morfín, "Los parroquianos”. A fines del siglo xviII, 50\% de los bautizos del Sagrario fueron de españoles. Gonzalbo Aizpuru, Familia y orden colonial, p. 230.

60 Márquez Morfín, "Disease and society”, pp. 6-8; Márquez Morfín, Sociedad colonial.

${ }^{61}$ Márquez Morfín, "Disease and society", pp. 6-8; Márquez MorFín, Sociedad colonial. La metodología toma en cuenta el grado de severidad. En San Juan fueron: ligero (31\%), moderado (20\%) y severo (17\%). Evalué la incidencia en cada hueso. El más afectado es la tibia; se comparó el grado severo en las series. Márquez y Meza, "La sífilis en la ciudad de México”. 
sífilis desarrolla el periodo terciario, cuando afecta al esqueleto, tomando en cuenta la susceptibilidad biológica individual. De ahí la certeza del grave problema de salud pública, no sólo de las prostitutas, sino de otros fragmentos sociales de la población de la ciudad de México. Esta información es relevante como evidencia de la sífilis entre las personas enterradas bajo el piso de la nave de la Catedral, quienes en sus esqueletos manifiestan la enfermedad. La serie ósea compete tanto a gente de estatus alto como probablemente también a otros sectores sociales, inhumados durante los siglos XVII al XIX.

La situación relajada y permisiva en las ciudades, junto con otros factores, explica la alta ocurrencia de una infección de carácter sexual. Varios elementos describen el comportamiento y hábitos en torno a la sexualidad de los capitalinos. La composición de las familias en los distintos grupos étnicos, el hacinamiento, la convivencia de parientes y no parientes en las viviendas, las relaciones fuera del matrimonio, los delitos sexuales, la bigamia, el amancebamiento, el adulterio, la separación conyugal e incluso la violación de doncellas ${ }^{62}$ representan circunstancias idóneas y el vehículo eficaz para el contagio. Para el siglo xIx se cataloga a la ciudad de México como un sitio donde la sífilis, blenorragia y gonorreas son comunes para los pobres y "gente sin escrúpulos", no distante de lo ocurrido en Francia o Italia. La evidencia física no deja lugar a duda de la dispersión del contagio en todos los sectores sociales, a pesar de la actitud de los médicos, cuyos preceptos y normas impedían emitir el posible diagnóstico de sífilis cuando el afectado era una persona considerada decente, o de familia con posición social

${ }^{62}$ González Aizpuru, Familia y orden colonial. 
y prestigio; el dictamen médico se enmascaraba por la connotación vergonzante implicada. El doctor Alfaro, médico de San Juan de Dios, publicó en La Gaceta Médica de México: "Para el vulgo sólo son sifilíticos aquellos individuos cuya necesidad obliga a acudir a los hospitales en solicitud de cama, y las personas decentes, que olvidando sus principios, se abandonan o se han abandonado a una vida desordenada". ${ }^{63} \mathrm{El}$ mismo médico aclara que impuso con gran disimulo tratamientos específicos a una familia cuyos miembros estaban contagiados de sífilis, sin que lo hubieran sospechado: "[...] (por supuesto con favorable éxito, vergonzante si se quiere); porque a pesar del tal éxito, se tomaría por atentado imperdonable, haber asistido como sifilíticos a los miembros de una familia decente" ${ }^{64}$ En los círculos sociales altos la sífilis era tratada con discreción y reserva por parte de los médicos, temerosos de diagnosticar al paciente y su familia, sobre todo si se trataba de un miembro distinguido de la sociedad. ${ }^{65}$ Este término - sifilítico - era reservado para los pobres, desamparados, para la plebe que abundaba en la ciudad y que recurría a los hospitales.

Los niños, el grupo más débil, no escaparon al terrible mal. En la información histórica sobre la sífilis congénita temprana o tardía, adquirida ya sea por vía intrauterina al feto o duran-

${ }^{63}$ Después de un año de tratamientos el médico le informó al paciente su estado sifilítico y le recomendó ir a París para consultar especialistas. Alfaro, "Sifilografía”, pp. 488-496.

${ }^{64}$ Alfaro, "Sifilografía", p. 496.

${ }^{65}$ Carrillo, "Control sexual”, p. 65, menciona que "En el México de principios del siglo xx, la sífilis era un grave problema colectivo de salud, pero por prejuicios, los médicos solían actuar como si no existiera”. Véase también Estrada URroz, "Control sanitario o control social”, pp. 21-25. 
te el nacimiento, abundan los ejemplos con declaraciones de la enfermedad y sus diferentes estadios, como en el caso de una pareja con sífilis. La mujer manifestó estar embarazada y posteriormente parió una niña con huellas del padecimiento:

La niña lloraba y gritaba; y mostraba señas claras de sífilis en las palmas de las manos, sobre las nalgas, en los labios inferiores; en la boca, en las fosas nasales; además presentaba diarrea, comía poco. [...] a pesar de los intentos por salvarla con el bicloruro, se tuvo que suspender la pócima, ya que la niña no la toleraba, así fue que falleció el 7 de julio. ${ }^{66}$

De hecho había familias completas contagiadas, incluidos niños pequeños, infectados in utero o bien durante el parto. ${ }^{67}$ Médicos como Francisco Poincy Leal y Victor Salle, estudiosos del efecto de la sífilis en niños, ${ }^{68}$ describen el contagio por herencia en el caso de los padres sifilíticos, así como la alta frecuencia de abortos:

${ }^{66}$ Salle, "De la sífilis congénita y hereditaria”, pp. 24-28.

${ }^{67}$ El doctor Alfaro describe: "Este hombre tenía cuatro hijos también sifilíticos, una niña de 3 años y medio con erupción pústulo-crustácea de la cabeza y con microdontismos, sorda, además tenía un crecimiento anormal de la cabeza. El otro hijo de 11 meses también presentaba agrandamiento de la cabeza, sin dientes, con constipación habitual, estreñimiento". Alfaro, "Sifilografía", pp. 488-496.

${ }^{68}$ SALLE, "De la sífilis congénita y hereditaria". El autor hace un recorrido histórico desde la aparición de la sífilis en 1495 y continúa con los estudios de dicha enfermedad en Europa; presenta 18 apartados breves y dos observaciones. El primer apartado se titula "La sífilis congénita y hereditaria", el segundo "Influencia de la madre"; el tercero, "Influencia del padre"; el cuarto, "Sífilis antes del nacimiento. Influencia de la enfermedad sobre la marcha del embarazo". El quinto se titula "Época de la aparición de la enfermedad"; el sexto, "Síntomas". Clasificación: S-T, 1870, ROA (exp. 2). 
En todo feto o todo niño en la primera edad que lleve sobre la piel, las mucosas, o las vísceras, una señal de la Sífilis hereditaria, el sistema huesoso está alterado. La sífilis en el feto es necesariamente mortal, siendo el niño expulsado antes de término o muriendo poco después del nacimiento. ${ }^{69}$

Los médicos reconocían a estos individuos como vulnerables. Fernández de Lara, quien trabajó en el Hospital de San Andrés y fue ayudante en el Consultorio de la Beneficencia Pública, afirma lo siguiente:

Se ha reconocido que la sífilis hereditaria presenta mucha gravedad; pero no diremos como algún autor, que: 'niño sifilítico, niño muerto'. Los excesos de todo género, el frío, la humedad, los cambios bruscos de temperatura, tienen una funesta influencia sobre la sífilis. Por el contrario, la edad, la buena constitución y sobre todo las buenas condiciones higiénicas los mejores adyuvantes en la medicación. ${ }^{70}$

Dichas observaciones las pude constatar al revisar algunos esqueletos de niños del convento de Santa Isabel (alre-

${ }^{69}$ Poincy Leal, "Estudio práctico sobre la sífilis". En los cuadros estadísticos reportados por el doctor Eduardo Liceaga, miembro de la Inspeción de Sanidad, del Consejo Superior de Salubridad, en 1896 se reportan 105 abortos y 11 nacidos muertos en el mes de julio, sin mencionar la causa de la muerte, de un total de 1252 defunciones en la ciudad de México. Se calcula una mortalidad por 1000 de 3.63. Mortalidad habida en la ciudad de México en el mes de julio de 1896 y noticia de las principales enfermedades que la causaron, con expresión del número de defunciones ocurridas para cada una de ellas. Boletín del Consejo Superior de Salubridad, II: 2 (31 ago. 1896), p. 44.

70 BMM. Academia Nacional de Medicina. Clasificación: S-T, 1870, HIG (exp. 5). 
dedor de 125 niños, desde fetos, recién nacidos y en otras edades) con modificaciones óseas asociadas que no dejan lugar a dudas sobre el impacto en los infantes. El estudio de esta serie esquelética revela lo importante y extendido del padecimiento. ${ }^{71}$

\section{LOS SOLDADOS Y LA SÍFILIS}

La población de riesgo para el contagio sifilítico era la gente joven, entre ellos los soldados, donde predominaban indígenas y castas. Reportes de soldados contagiados son constantes desde el siglo xviII. ${ }^{72}$ La cifra de 4500 enfermos atendidos en el Hospital del Amor de Dios en 1781 certifica el hecho. ${ }^{73}$ Los médicos hacían revisiones de los aquejados, describían las lesiones presentes y emitían sus diagnósticos. Un alto porcentaje de hombres jóvenes dedicados al ejército fueron enviados a San Juan de Dios o a San Andrés para su atención. ${ }^{74} \mathrm{El}$ control de los soldados y los reconocimientos efectuados al per-

${ }^{71}$ Investigación en curso en la Escuela Nacional de Antropología e Historia a cargo de Lourdes Márquez. El estudio detallado requiere de un análisis exhaustivo para identificar las lesiones y poder efectuar el diagnóstico diferencial con otros padecimientos que pudieran dejar huellas similares. Sin embargo, en los resultados preliminares la frecuencia de sífilis congénita parece alta, lo cual confirma lo extendido del problema sanitario.

72 AGN, Indiferente Virreinal, c.-exp. 6369-014, Hospitales, Año 1760, fs. 16, Hospital de San Juan de Dios, en Valladolid. Reconocen enfermos de sífilis. "Juan Francisco del Hoyo padece una antigua gonorrea sifilítica incurable”. Zacatecas a 4 de agosto de 1815. Rúbrica. AGN, Operaciones de Guerra, vol. 901, exp. 12.

${ }_{73}$ Muriel, Hospitales de la Nueva España, pp. 158-159.

${ }^{74}$ Localizamos varios documentos sobre sifilíticos en diversas partes del país. AGN, Indiferente Virreinal, c. 3258, exp. 18, Hospitales, Año 1792, fs. 8. 
sonal descubren lo complejo de la enfermedad, agravada por un conjunto de padecimientos y de síntomas ("almorranas sifilíticas, gonorrea sifilítica, bubas bolas”). La duración de la infección es extensa (algunos casos duran años, sin probabilidad de curarse), su gravedad, los tratamientos y algunos signos de las lesiones, en especial las bubosas, el chancro, o bien se nombra "el mal gálico", las pústulas, forman parte de las descripciones clínicas. En ocasiones estos hombres llegaban tan graves al hospital que morían al poco tiempo, como fue el caso de José Bedoya Rubín. ${ }^{75}$ Localizamos algunos reportes de los casos remitidos al hospital, por ejemplo:

[...] Ban [sic] por delante los enfermos que son seis. El primero como más antiguo, que lleva seis años que se está curando, y no acaba de ser bueno, se llama Pablo Barela [...]. El otro es Pascual de los Reyes muchachón, que esta buboso. El tercero es Pablo de Sn. Joseph, que lleva seis meses, que está malo de unas bolas que dice tenía en el vientre, y no se le acierta a curar. El cuarto es una hija de este Pablo doncella, que es muchacha y también adolece de bubas. El quinto enfermo es una muda llamada Agustina Ramos [...]. El último enfermo es Chelipa Soles remasada de bubas, y la por enfermedad el no conozca, ni confesar su accidente y discurro que hasta la campanilla se le a $[s i c]$ cernido $[\ldots]]^{76}$

En plena guerra de independencia el número de soldados sifilíticos iba en aumento. En Valladolid registraron 80 sol-

75 AGN, Indiferente Virreinal, c. 3258, exp. 18, Hospitales, Año 1792, fs. 8. Murió en el hospital en junio de 1793, un año después de su ingreso. AGN, Indiferente Virreinal, c. 6719, exp. 20, Hospitales, Año 1793, fs. 2. ${ }^{76}$ AGN, Indiferente Virreinal, c. 6130, exp. 15, Jesuitas, Año 1756, fs. 2. 
dados enfermos. El oficial encargado relata: “[...] los setenta y seis de venéreo y ya me faltan las fuerzas y arbitrios para tomar precauciones y medidas [...] asegurando a V.E. sin exageración es esta la ciudad más viciosa e inmoral en todas sus clases que yo he visto Dios guarde a V.E. [...]". ${ }^{77}$ En Guanajuato descubren un caso de "gonorrea virulenta" y lo tratan con mercurio. La severidad de las lesiones en ocasiones incapacitaba a la persona para realizar su trabajo. Los documentos abundan en descripciones: "virus sifilítico inveterado, como lo demuestran las úlceras que tiene en las fauces a gonorrea que es de mala calidad y los continuos dolores en los huesos, todos estos síntomas indican que se halla la masa de la sangre apoderada de dicho virus $[\ldots]]^{78}$ En Acapulco tomaban precauciones ante la sospecha de soldados del batallón procedente de Filipinas dominados de algún mal venéreo. El comandante de la fragata Concepción pidió el reconocimiento, por el cirujano de la plaza de Acapulco, de los sargentos y los cabos de los batallones para que no desembarcaran. ${ }^{79}$ De acuerdo con el estudio de Ana María Carrillo, en 1881 Francisco Montes de Oca, médico militar, calculó que probablemente había entre uno o dos tercios de militares asistidos por enfermedades venéreo sifilíticas en el Hospital Militar de Instrucción. En el reporte de los hospitales, entre 1881 y 1885 había 12886 infectados. ${ }^{80}$ Las enfermedades venéreas son acompañantes cotidianos de

\footnotetext{
77 AGN, Operaciones de Guerra, vol. 810, exp. 68, 4 fs. (4 de mayo de 1811), fs. 293-296.

${ }^{78}$ A GN, Instituciones Coloniales, Indiferente Virreinal, c. 2173, exp. 29 (1812), 6 fs.

79 AGN, Gobierno Virreinal, Marina, vol. 194, exp. 2 (1803), fs. 29-149.

80 Carrillo, "Control sexual”, p. 72.
} 
los soldados. La soledad, el distanciamiento de sus parejas y el relajamiento moral y sexual son "el caldo de cultivo" para el contagio y diseminación de la infección. Entre mayor es el número de parejas sexuales, mayores las posibilidades de enfermar. Al igual que se culpaba a las prostitutas de ser la fuente del contagio, las soldaderas, compañeras de mucho militares, eran vistas como el centro de infección. ${ }^{81}$

EL GRUPO MÁS VILIPENDIADO: LAS PROSTITUTAS

Las ideas imperantes en la segunda mitad del siglo xIX respecto de la enfermedad están enmarcadas en dos líneas: la concepción médico moral de estos padecimientos como castigo divino por una conducta promiscua y los nuevos y modernos conocimientos médicos de clínica, diagnóstico y bacteriología durante el porfiriato. ${ }^{82}$ Las corrientes francesas a la vanguardia del estudio sobre la sífilis instaban a instituir medidas de control sanitario y la vigilancia estuvo enfocada exclusivamente en las prostitutas como elemento primordial y centro neurálgico del padecimiento venéreo. ${ }^{83}$ La tolerancia hacia el ejercicio de la prostitución fue normada con la promulgación, el 17 de febrero de 1865, del Reglamento basado en el sistema francés. La encargada de llevar el registro de las prostitutas fue la oficina de Inspección de Sanidad, centro administrativo dependiente del Consejo Superior de Salubridad. El primer paso consistió en levantar un padrón de mujeres públicas con datos sobre su resi-

81 Carrillo, “Control sexual”, p. 74.

82 El surgimiento de la salud pública moderna es ampliamente analizado por CARRILlo “Economía, política”, pp. 67-87.

83 Carrillo, “Control sexual”, pp. 65-77. 
dencia, ya fuera en burdeles, casas de citas o de asignación, con el fin de cobrarles impuestos fijados por el Estado para autorizar el ejercicio de la prostitución. Las mujeres estaban obligadas a ser revisadas por el inspector una vez a la semana y a pagar, con la misma frecuencia, una cantidad determinada por el permiso. A finales del siglo incluso se recomendó que la inspección fuera efectuada dos veces por semana. Bajo estos preceptos, las autoridades intentaron ordenar preservar la moral de la población, controlar la diseminación de la enfermedad y evitar el contagio. Si bien la estrategia regulaba las actividades alrededor de las prostitutas como el sector sifilítico más visible y vulnerable, el otro gran segmento compuesto por los clientes de las meretrices, las esposas y los hijos víctimas de este mal venéreo, estaban en el anonimato impuesto socialmente ante tan desagradable enfermedad y su método de transmisión asociado a la lujuria, el deseo, el libertinaje, la infidelidad, el engaño, el estupro, la violación. La realidad presentaba los estragos de la sífilis y su cobertura entre los habitantes de la capital, incluida la "gente decente y honesta" desde siglos atrás. El modelo higienista consideraba como una solución regular mantener recluidas (se mencionaba la palabra secuestradas) a las sifilíticas en los hospitales, o bien en sus casas. ${ }^{84}$ El encierro no siempre fue exitoso y varias se fugaron, huyeron del hospital o del lugar donde habían sido confinadas. Rosa García fue puesta a "disposición de C. Gobernador por prófuga reincidente y además [...] por no haber satisfecho sus costas" ${ }^{85}$

${ }^{84}$ Carrillo, “Control sexual”, pp. 65-77; Carrillo, “Economía, política”, pp. 67-87.

${ }^{85}$ AHSSA, Salud Pública, Inspección antivenérea, c. 2, exp. 19, f. 16. 
El enfoque médico, la percepción del enfermo, las medidas implementadas por las autoridades sanitarias son temas recurrentes en el estudio de salud pública concerniente a las actividades sexuales. Pilar Gonzalbo menciona que la alta proporción de mujeres solas, "de las cuales la mayoría vivía fuera del hogar paterno, era un elemento de desequilibrio en las familias y peligrosa tentación para los previsibles arrebatos sexuales masculinos". ${ }^{86}$ Otros aspectos sugestivos para entender la correspondencia entre las enfermedades de origen venéreo y el comportamiento de la sociedad capitalina fueron en general "la vida licenciosa", el trato con "mujeres públicas" y las múltiples casas de tolerancia. La ideología, las creencias y el relajamiento de la sexualidad. El reconocimiento sanitario, decían las autoridades: "tiene por exclusivo objeto separar de la sociedad aquellas infelices, que por estar enfermas, pueden ser causa de la propagación de la sífilis, y por esto solo tiene el carácter de una medida de policía sanitaria". ${ }^{87} \mathrm{Sin}$ embargo, la inspección representaba una carga onerosa para las jóvenes cercadas con grandes deudas por "costas", refrendos y multas. Los inspectores denunciaban la falta de pago. El registro distinguía el lugar de trabajo en prostíbulo o de manera independiente; en algunas calles las jóvenes rondaban desde el anochecer en busca de clientes, practicaban por su cuenta y seguramente también eran vigiladas y presionadas por la policía. Las autoridades definieron tres zonas de tolerancia de acuerdo con categorías (primera, segunda y tercera), delimitando el espacio urbano lo más alejado posible del área comercial, habitacional y de

\footnotetext{
${ }^{86}$ Gonzalbo Aizpuru, Familia y orden colonial.

${ }^{87}$ AHSSA, Salud Pública, Inspección Antivenérea, c. 2, exp. 19, fs. 1, 2v.
} 
recreación de la gente acomodada. Los burdeles correspondían a diferentes categorías según el costo. Los prostíbulos albergaban alrededor de media docena de meretrices al cuidado de la "matrona". Abundaban los burdeles clandestinos, como el de Antonia Vázquez. Respecto de este lugar se reportó un caso de violación, que quizá no fue un hecho aislado:

Bonifacia Flores (menor de 14 años), la que expresó fue desflorada en un burdel [...] situado en la calle el Arco no. 10 [...] la virginidad de esta niña fue vendida y de su precio nada recibió [...] dicha niña resultó con Chancros blandos en las ninfas por lo que se le envió al hospital, la madre la busca con empeño [...] México, julio 9 de $1874 .{ }^{88}$

La situación sanitaria y los datos epidemiológicos de las prostitutas constituyen un tema fundamental, dado que una de las fuentes de información que hemos utilizado son los esqueletos de algunas de estas mujeres del Hospital de San Juan de Dios, los cuales revelan información epidemiológica aunada al cúmulo de datos históricos publicados. A partir del Registro de Mujeres Públicas de la Ciudad de México (1865) elaboramos algunas estadísticas: 80\% tenían entre 15 y 25 años de edad; incluso se anotó una niña de 13 años, que era la más pequeña del grupo; entre 26 y 30 años, $11 \%$, y muy pocas rebasaban los 39 años (gráfica 4).

El doctor Ramírez de Arellano relata la problemática social en torno a las niñas desamparadas que deambulan por las calles vendiendo "cerillos y papeles, o bien implorando la

${ }^{88}$ AHSSA, Salud Pública, Inspección Antivenérea, c. 2, exp. 19, f. 30. 


\section{Gráfica 4}

DISTRIBUCIÓN POR EDAD A PARTIR DEL REGISTRO

DE MUJERES PÚBLICAS. 1865

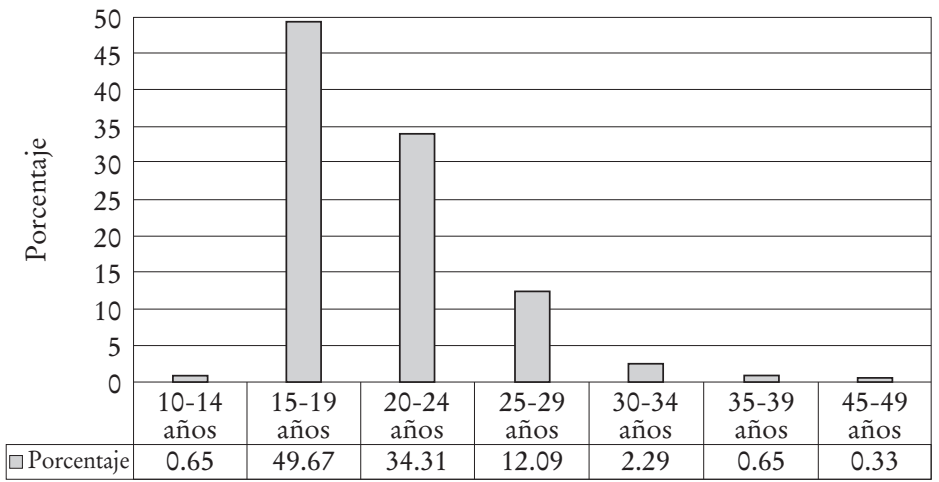

Fuente: Registro de Mujeres Públicas de acuerdo al Reglamento de 1865, Fondo Reservado, Instituto de Salud Pública. Total de mujeres: 306 de 334 registradas.

caridad pública, [que] son sin duda alguna candidatos obligados para la prostitución mañana. [Denuncia que] jóvenes menores de edad están ya provistas de una patente expedida por la Inspección de Sanidad”. ${ }^{89}$

Respecto del lugar de origen, $47.9 \%$ eran nativas de la ciudad de México y $49 \%$ habían inmigrado de otras partes (gráfica 5). Una de ellas era alemana y había dos francesas procedentes de Nueva Orleans. Por medio de las imágenes: vestido, peinado y otras características, es posible identificar aquellas de origen indígena, pues llevaban sus trajes típicos, rebozos, faldas, blusas, el cabello peinado en trenzas o suelto. Seguramente no todas conservaban su indumentaria

89 Boletín del Consejo Superior de Salubridad, II: 4 (31 oct. 1896). 


\section{Gráfica 5}

LUGAR DE ORIGEN DE MUJERES PÚBLICAS. REGISTRO DE 1865

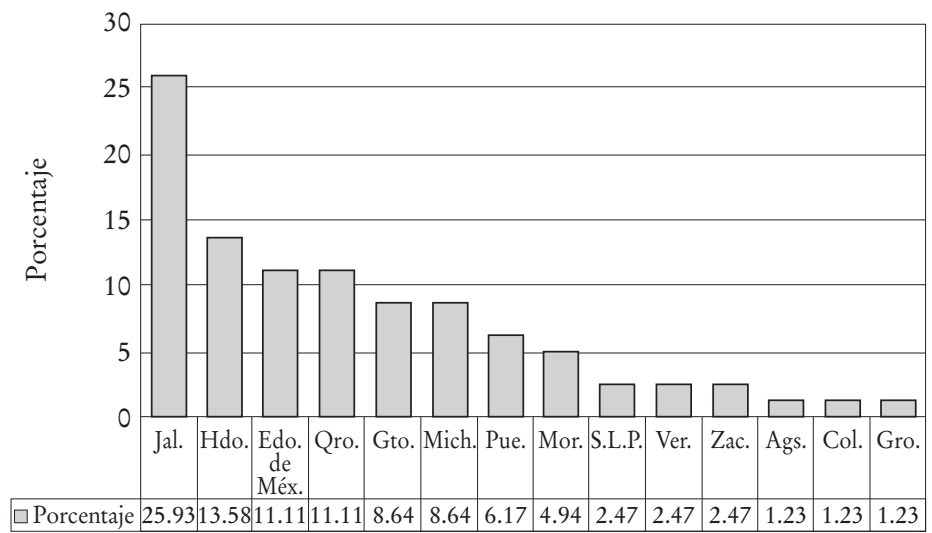

Funnte: Archivo del Instituto Nacional de Salud Pública, Registro de mujeres públicas, 1865.

y debieron adoptar los trajes europeos (figura 2). Abundan las mujeres que llevaban sombrero y vestidos elegantes. El documento registra la ocupación; muchas decían ser sirvientas, costureras, planchadoras, lavanderas, etcétera. ${ }^{90}$

\section{LAS EVIDENCIAS, LOS TRATAMIENTOS}

Y FORMAS DE CONTAGIO

Las ideas imperantes provenían de médicos europeos: Philippe Ricord (1837) reconoció la especificidad de la sífilis como una entidad diferente de la gonorrea y estableció sus tres estadios. Su discípulo Alfred Fournier, demostró, por medio

${ }^{90}$ Archivo Histórico del Instituto de Salud Pública, Registro de Mujeres Públicas, 1865. Cuernavaca, Morelos. 
Figura 2

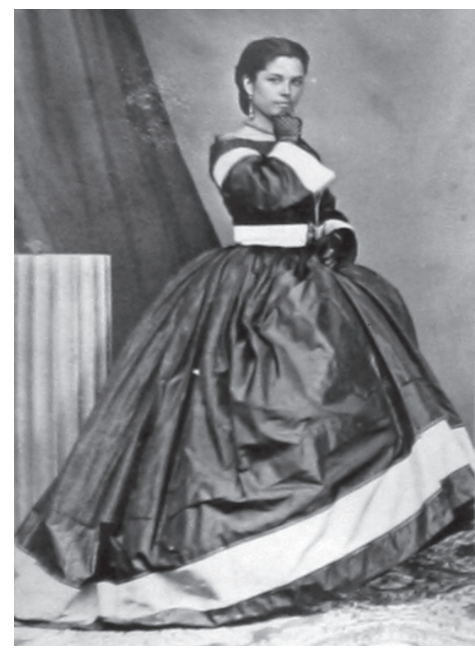

Guadalupe Romero, de Temascaltepec.

Archivo Histórico del Instituto Nacional de Salud Pública.

del análisis estadístico de las historias clínicas tanto de su clientela privada como de los enfermos que acudían al hospital, que la sífilis contagiada por los padres jugaba un papel considerable en la mortalidad de la infancia. La sífilis era por tanto un serio factor de despoblación, tema de gran significación para la sociedad europea, en ese momento a la vanguardia de la investigación. ${ }^{91}$ El diagnóstico de los enfermos sifilíticos se basaba en la observación del tipo de lesiones, signos, síntomas y características particulares como son las manifestaciones en varios órganos del cuerpo, huellas en la cara, depresión de los huesos de la nariz, modificación de los dientes, daños en la piel, chancros, pústulas, entre otros.

91 Obregón, “Médicos, prostitución”, pp. 161-186. 
Por su carácter crónico la sífilis se desarrolla en tres etapas con duración variable pero prolongada, elemento fundamental para su dispersión. En las primeras manifestaciones aparece el chancro, que es indoloro y desaparece en pocos días. Tiempo después (segunda etapa latente, variable de semanas a meses), los "accidentes" - expresiones de la enfermedadadquieren importancia por su amplitud en diversas partes del cuerpo, lo cual influye para acudir al médico con cierta alarma y temor. La sífilis terciaria afecta diferentes órganos de forma progresiva, incluyendo el esqueleto ( 3 a 10 años), de ahí que podamos identificarlo mediante las lesiones sifilíticas. ${ }^{92}$ La mayoría de las descripciones de médicos de la época se refieren a las lesiones de las etapas primaria y secundaria. En 1877 en el Hospital Morelos reportaron el caso de "Francisca Galindo de 24 años, viuda, natural de Pénjamo, vendedora del cuartel de San Ildefonso, de temperamento linfático; vino voluntariamente solicitando un lugar para su curación [el médico] puso su diagnóstico de esta manera: 'Chancros blandos sobre el gran labio derecho, acompañados de un edema agudo en dicho punto'". ${ }^{93}$ Estas lesiones permiten reconocer la infección, momento cuando el contagio se materializa, las huellas de la enfermedad venérea son inequívocas y se registran como terribles e incurables, a pesar de las proclamas de médicos, boticarios y farmacéuticos sobre el éxito de sus procedimientos basados en el popular mercurio, usados desde siglos atrás.

\footnotetext{
92 Hackett, Diagnostic.

93 Poincy Leal, "Estudio práctico". La teoría humoral estaba en su apogeo, de acuerdo a las descripciones de los enfermos, a quienes se califica de temperamentos: linfáticos, nervioso o sanguíneos.
} 
El mercurio era el paliativo más importante, considerado específico para la curación. La mayoría de los tratamientos incluían por ejemplo bicloruro de mercurio (licor de Van Swieten) en gotas, yoduro de potasio en dosis desde dos a cuatro gramos diarios, en un vaso de leche azucarada, las píldoras de Dupuytren hasta la salivación, etc. Los especialistas consideraban el uso de las inyecciones hipodérmicas de sublimado de mercurio para los casos crónicos, a pesar de las discusiones sobre sus efectos secundarios. De acuerdo al estadio de la enfermedad los tratamientos podían variar. Cuando estaban en su fase secundaria, en la cual aparece erupción en espalda, pecho, vientre y miembros superiores e inferiores, recetaban píldoras de calomel y extracto de opio y para los dolores articulares un compuesto de trementina, láudano de Rousseau y cloroformo. ${ }^{94}$ Los ungüentos se aplicaban en las lesiones. ${ }^{95}$ En los bubones administraban vino aromático con sulfato de cobre y embrocación con tintura de yodo. En el caso de que no hubiera ningún alivio, los médicos seguían experimentando con diferentes sustancias. Algunas veces los tratamientos parecían dar resultados, sin embargo hubo personas que regresaron al médico después de diez años, lo que indicaba una nueva infección con síntomas muy violetos y rápidos, o bien el paso del estadio latente al terciario. ${ }^{96}$ Otro tipo de tratamientos consistían en cauterizar el chancro en el quirófano para extirpar las "lesio-

\footnotetext{
94 Poincy Leal, "Estudio práctico".

95 AGN, Instituciones coloniales, Real Hacienda (90), vol. 82, exp. 3, fs. 41-54 (1797-1800). En el Hospital de San Andrés, en el Departamento de Gálico se administraban las unciones dos veces al día.

96 Poincy Leal, "Estudio práctico”, pp. 32-33 y 41-42.
} 
nes más escandalosas y molestas causadas por la sífilis". ${ }^{97}$ La vergüenza y el temor ocasionado al percatarse del contagio llevaba a la automedicación. Un hombre de 35 años, "comerciante, de temperamento sanguíneo y de constitución robusta [...] fue atacado por una blenorragia [...] temeroso se aplicó unas inyecciones que un amigo le aconsejó de una receta, que eran de nitrato de plata". ${ }^{98}$ El grupo de especialistas era muy amplio, médicos practicantes en el hospital de San Juan de Dios y en el pabellón de gálico de San Andrés, entre los que se menciona a los doctores Andrade, Lobato, Ángel Gutiérrez, Gustavo Ruiz Sandoval, Alfaro y una multitud de alumnos.

\section{LAS FORMAS DE CONTAGIO}

El contagio más frecuente era por medio de las relaciones sexuales. Los médicos europeos y mexicanos tenían plenamente identificadas las maneras de trasmisión. ${ }^{99}$ Los médicos

97 De la Garza Velasco, "Breves apuntes sobre la cauterización”.

98 Casillas, “Tratamiento”.

99 En especial en Francia Philippe Ricord y Alfred Fournier. En México La Gaceta Médica (GMM) publicó múltiples estudios médicos sobre la sífilis. Entre ellos resaltan los siguientes: doctor Emilio del Raso, "Suero diagnóstico de la Sífilis”, GMM, t. 1, ANM, México, 1920, pp. 17-23. Doctor Perrin, “Conclusiones de Patiño Mayer y Gourdy sobre el Leuco diagnóstico y Leuco pronóstico de la Sífilis”, GMM, t. 1, ANM, México, 1920, pp. 30-58; doctor Ángel Binaghi, "Pomada de Cirilo en la lúe venérea”, GMM, t. III, ANM, México, 1838, pp. 273-275. Este médico italiano fue reconocido en la sociedad mexicana del siglo xIX por sus aportes a la medicina mexicana de esa época, aunque sabemos que dicha pomada no ayudó en mucho a los enfermos. Carpio [Hidalgo], "Úlceras Venéreas de la garganta”, GMM, t. II, ANM, México, 1837, pp. 388-389. F. Lereboullet, "Sífilis Hereditaria y menorragias" (originalmente publicado en París 
estaban dejando atrás las concepciones del castigo divino y de los aires pútridos para llegar a la era de los virus y las bacterias como responsables de algunas enfermedades, a la medicina moderna y científica. ${ }^{100}$ Librado Vega lo describe así:

El virus sifilítico es uno, su naturaleza es siempre la misma y se admite que siendo casi siempre secretado por las partes genitales, ordinariamente durante las relaciones sexuales infecta a los individuos, pues este mismo virus absorbido y entrando en el torrente circulatorio, infectando la economía al producir accidentes que corresponden a la sífilis constitucional, y que son

Médica), GMM, t. I, ANM, México, 1919, pp. 375-376. B. Dujardin, "La Sífilis ignorada”, GMM, t. I, ANM, México, 1919, pp. 183-184. Francisco Montes de Oca, "Aneurisma Femoro Poplíteo. Complicando una sífilis constitucional”, GMM, t. 4, ANM, México, 1869, pp. 134-137. Eduardo Vegas, "Sífilis, Sífilis Hereditaria tardía en un niño de tres años y medio. Osteoporosis del tercio inferior de la tibia. Atrofia e insuficiencia funcional de los músculos tibiales anteriores y posterior.- Desviación del pie en valgus.- Dificultades para fundar el diagnóstico etiológico.- Curación”. GMM, t. 27, ANM, México, 1892, pp. 304-312. M. Alfaro, "Sifilografía. Ataxia locomotriz incipiente de naturaleza sifilítica. Heredo-sífilis". GMN, t. 26, ANM, México, 1891, pp. 488-496. Alfonso Ortiz, "Síntoma ano-rectal. Fístulas infra y supra esfinterianas, complejas, sintomáticas. - Curación. Clínica Externa”. GMM, t. 31, ANM, México, 1893, pp. 133-136. Domingo Calderón, "Patología, Pólipo fibroso intra-uterino", GMM, t. 3, ANM, México, 1867-1868, pp. 139-140. Es el caso de una mujer casada de 32 años, con 6 hijos. Demetrio Mejía, "Observación de Pólipo fibroso uterino”, GMM, t. 18, ANM, México, 1883, pp. 177-182. Es el caso de una mujer de 40 años, de oficio cocinera, originaria de Huehuetoca. Ildefonso Velasco, "Pólipos mucosos nasales. Sostenidos probablemente por un vicio sifilítico", GMM, t. 8, ANM, México, 1873, pp. 105-108. A. Villalobos, "Ginecología, Pólipo fibroso intra-uterino", GMM, t. 19, ANM, México, 1884, pp. 107-109. Rafael Lucio, "Patología, Aparición y desaparición, alternativas de pólipo uterino", GMM, t. I, ANM, México, 1864-1865, pp. 19-21.

100 Carrillo, “Economía, política”, pp. 67-87. 
tan frecuentes por parte de la piel, las mucosas, si no ha cambiado de naturaleza, si es el mismo que ha producido los accidentes primarios por el simple contacto, podrá por el mismo motivo comunicarse de un individuo a otro. ${ }^{101}$

A comienzos del siglo xx, a la luz del conocimiento de las enfermedades infecciosas proporcionado por la bacteriología y la inmunología, surge el concepto moderno de sífilis, al conjuntarse tres hallazgos - el agente causal, el test diagnóstico y el Salvarsán. En 1905, la Oficina Imperial de Sanidad de Alemania y su equipo de bacteriólogos y zoólogos identificó en tejidos sifilíticos al agente etiológico. El microorganismo fue denominado Spirochaeta pallida y al ser inoculado en animales de experimentación probó ser el agente causal. Un año más tarde se desarrolló la reacción de Wasserman para diagnosticar la enfermedad. Paul Ehrlich popularizó en 1909 el uso del Salvarsán, compuesto arsenical. El arsenobenzol causaba la desaparición total de los síntomas sifilíticos. La nueva droga fue llamada neosalvarsán o 606. ${ }^{102}$

Otra forma de contagio o transmisión era por medio del amamantamiento. Los enfermos podrían ser la nodriza, la madre o el niño. Cuando el bebé era el infectado era menos problemático. Por este motivo las autoridades de salud requerían la revisión médica de la nodriza y el certificado de salud; continuamente observan casos de transmisión de acci-

101 VEGA, "Los accidentes secundarios".

102 Obregón, “Médicos, prostitución”, pp. 165-169. En La Gaceta Médica se publicó un trabajo sobre el tratamiento de la parálisis y de la sífilis cerebral por medio de inyecciones de Salvarsán en las carótidas. M. Woch, 1919, núm. 23 (traducción de Izquierdo). “De todas partes”, GMM, t. 1, ANM, México, 1920, pp. 364-365. 
dentes secundarios entre niños de pecho y sus nodrizas. ${ }^{103}$ A principios del siglo xx esta situación motivó la emisión de normas en el código sanitario; se incluyeron algunos artículos sancionando a la nodriza que conociendo su enfermedad amamantara a un niño, pues lo ponía en riesgo de contagio. En ocasiones, nodrizas sin ninguno de los síntomas aparentes de la afección contagiaron al niño y esto se atribuía a la leche. ${ }^{104}$ En un estudio presentado en 1916 a la Comisión Revisora del Código Penal acerca de "un nuevo delito: el contagio (sexual y nutricio)", se trata de establecer un castigo para aquellas personas enfermas que contagien a otros. Se integran los siguientes artículos al Código Penal:

Art. 526.-Si una nodriza o ama sabe o sospecha que se encuentra atacada de sífilis, no podrá amamantar al hijo de otra persona. Art. 527.-Los niños que padezcan sífilis no podrán confiarse, para ser amamantados, a otra mujer que no sea su madre. En caso de que, según dictamen, sea imprescindible la alimentación natural, podrá confiarse la amamantación del niño a una nodriza sin hijos de pecho, la que no podrá amamantar a otros sanos. ${ }^{105}$

El peligro de esta enfermedad infecto contagiosa de carácter crónico es que, aun cuando la persona no tuviera signos visibles, por encontrarse en estado latente, el riesgo de contagio existe. Así, hombres que aparentemente estaban curados podrían "engendrar hijos que presentan síntomas sifilíticos

\footnotetext{
103 VEGA, "Los accidentes secundarios".

104 VEGA, "Los accidentes secundarios".

105 AHSSA, Salubridad Pública, Servicio Jurídico, c. 5 [p. guía 12], exp. $12,1916$.
} 
que los hacen sucumbir a los pocos días de su nacimiento”. ${ }^{106}$ Las autoridades en materia de salud tratan de mostrar los peligros de la infección crónica, el riesgo de infectar a la prole, y se establecen regulaciones para contraer matrimonio. ${ }^{107}$

Las campañas de vacunación contra la viruela, ampliamente extendidas en el país en el siglo XIX, se convierten en una contrariedad para las autoridades de salud. En el siglo XIx los médicos identificaron otras formas de contagio por medio de la inoculación mediante la vacuna brazo a brazo, procedente de niños enfermos de sífilis. Los médicos habían observado distintos casos de infecciones denunciados en la prensa, mediante una amplia y ríspida discusión entre los partidarios de la vacuna brazo a brazo y de la animal. Los intereses de uno y otro grupo traen a la luz la terrible situación desatada, ante lo que parece una amplia población infantil infectada con el padecimiento congénito. Al respecto se decía: "Se ha probado que si se vacuna a un niño con pus tomado de otro sifilítico y la punta de la lanceta lleva alguna gota de sangre, lo[s] síntomas sifilíticos se desarrollan en el niño que sufrió la operación”. ${ }^{108}$ La controversia es extensa en los escritos publicados por el doctor Ángel Iglesias, miembro de la Sociedad Médica de México, y el señor

106 VEGA, "Los accidentes secundarios”.

107 AHSP, Salubridad Pública, Servicio Jurídico, c. 5 [p. guía 12], exp. 12 (1926-1927). Síntesis: Modificaciones al código Penal. Contiene protestas del Departamento de Salubridad para modificar el Código Penal en lo relativo a delitos de contaminación sexual; estudios acerca de la creación de un delito de contagio sexual y nutrición; dictamen y observaciones sobre el mismo; modificación al Art. 527 sobre niños sifilíticos; consideraciones sobre las circunstancias que excluyen la responsabilidad penal, capítulos del código relativos al tráfico de drogas, la embriaguez, etcétera. 108 VEGA, "Los accidentes secundarios". 
Luis Muñoz, quien tenía un establecimiento ("de conservación y propagación de vacuna inglesa"). ${ }^{109}$ Este último relata: "Hace precisamente un año que establecí en mi casa las vacunaciones diarias de brazo a brazo: he vacunado cada mes más de cien niños pobres, y allí han encontrado siempre los profesores de medicina tubos con buena vacuna para el servicio de sus clientelas". ${ }^{110}$ La pugna entre Muñoz e Iglesias se hacía patente en la Memoria desplegada en 1864 por el doctor Depaul en la Academia de Medicina de París, en la cual se describían múltiples casos de niños infectados por la vacuna humanizada, con el fin de descalificarla como causante de contagio sifilítico y con ello promover la utilización de la vacuna animal. Muñoz esgrime argumentos en apoyo de la vacuna humana y culpa a los médicos de la falta de precaución y revisión de los niños para asegurarse de que estén libres de sífilis. Utilizando los datos franceses expuestos en la Memoria describe lo siguiente:

Una niña expósita de tres meses fue vacunada en Lueques con fluido tomado de un niño que estaba y que continuó siendo sano. Se desarrollaron en él pústulas regulares que sirvieron para inocular cuarenta y seis niños: y seis de estos últimos tuvieron pústulas normales con las cuales se inoculó a otros cien niños que no presentaron ulteriormente ningún síntoma sifilítico [...] El sistema glandular como el huesoso fueron igualmente afectados. [...] Estos accidentes se comunicaron a

${ }^{109}$ HN, La Revista Universal, Diario de Política, Religión, Literatura, Ciencias, Artes, Industria, Comercio, Agricultura, Variedades y Anuncios. (10 ago. 1868), D.F. "Remitidos", 4 de agosto de 1868.

${ }^{110}$ HN, El Siglo Diez y Nueve, suplemento al núm. 472, D. F. (28 oct. 1868), pp. 2-3. 
las nodrizas y a las madres de los niños. [...] el Dr. Cerioli, confirmó la naturaleza sifilítica de los accidentes que presentaban los niños y las nodrizas [...]. Diez y nueve niños murieron; los demás se restablecieron más o menos pronto [...]. Todas las mujeres infectadas curaron. ${ }^{111}$

[...] Para no omitir nada le diremos al público que las pústulas de la vacuna pueden convertirse en úlceras sifilíticas, en las personas o niños que tienen ya la sífilis constitucional, pero esto no es lo que se llama sífilis vacunal, ni puede ser imputado a la vacuna $[. .$.$] y no sería esto más que una manifestación de la sífi-$ lis que traían ya consigo. ${ }^{112}$

Muñoz argumentaba sobre las bondades en México de continuar aplicando la vacuna humana de origen inglés: "cuando se reflexiona, que esta cuestión en Europa conmueve grandes intereses, porque si la vacuna animal, en Nápoles ha podido hacer vivir cómodamente a sus propagadores, hoy promete enriquecer fabulosamente a los que en Francia la han prohijado". ${ }^{113}$ El relato de Muñoz tenía como objetivo demostrar que la vacuna brazo a brazo era inofensiva si se tomaba de niños sanos, no así si éstos tenían sífilis.

¿Se puede producir ésta por niños que presentan en el momento en que se usan, como vacciníferos, síntomas sifilí-

${ }^{111}$ HN, La Revista Universal (13 ago. 1868), D. F. Sección Científica. Memoria sobre la vacuna animal. Leída ante la Sociedad Médica de México, en la Sesión del $1^{\circ}$ de julio de 1868. Por Ángel Iglesias, miembro de dicha Sociedad.

${ }^{112}$ HN, El Siglo Diez y Nueve, suplemento al número 472, D.F. (28 oct. 1868), pp. 2-3.

113 HN, El Siglo Diez y Nueve, suplemento al número 472, D.F. (28 oct. 1868), pp. 2-3. La Gaceta Médica de México, núm. 12 del tomo III, f. 181. 
ticos? Podrá ser, y si llegaran a presentarse hechos reales de sífilis vacunal, no podrían ser más que éstos:

[...] Niños perfectamente sanos, es decir, en quienes no puede encontrarse ninguna manifestación sifilítica, por mucho que se busque, en quienes también los granos nada ofrecen de sospechoso, por su aspecto y coloración, usados como vacciníferos ¿pueden ocasionar la sífilis, por tenerla ellos latente? no lo creo absolutamente, pues el modo con que se han practicado aquí, por tantos años, las vacunaciones, es de ello perentoria prueba. No se hubieran dado entonces casos aislados y raros de la sífilis vacunal aquí; se hubieran visto a cada paso frecuentes epidemias, porque la sífilis es muy común en México. ${ }^{114}$

Desde el bando contrario Ángel Iglesias, impulsando la utilización de la vacuna animal, transcribe el relato de un caso en Baviera de ocho niños inoculados que se infectaron de sífilis:

[...] Tres meses después [de la vacunación] la mayor parte de estos niños, no ofrecían ya úlceras, pero tenían salientes aplastadas o en forma de verrugas en las partes genitales. [...] A la misma época aparecieron erupciones sospechosas en las madres y niñeras de los vacunados, grietas, condilomas en el ano y las partes genitales. [...] Yo pregunto: ¿es así como se produce la sífilis vacunal? Porque veo aquí todo menos vacuna. Más bien parece que si el hecho es cierto, a estos niños no se les puso más que el virus sifilítico solo. [...]. Vuelve uno a preguntar ¿hubo aquí vacuna? ¿es esto lo que se nos da como uno de los casos más mar-

114 HN, El Siglo Diez y Nueve, suplemento al número 472, D. F. (28 oct. 1868), pp. 2-3. Memoria del Sr. Iglesias. La Gaceta Médica de México, núm. 12 del tomo III, f. 181. 
cados de la sífilis vacunal? Yo, por mi parte, vuelvo a decir, si el hecho es cierto: a estos niños se les ha inoculado la sífilis [... ${ }^{115}$

Los argumentos vertidos permiten entrever la pugna en Europa y en México entre el grupo partidario de la utilización de la vacuna animal que era producida en Italia y Francia y el grupo promotor de la "humanizada”. La Sociedad Médica de México emitió un dictamen a favor de la vacuna animal, que fue publicado en el periódico Siglo XIX. Los progresos tendentes a aplicar esta vacuna avanzaban y en julio de 1868 el doctor Iglesias presentó la Memoria sobre el tema ante la Sociedad Médica de México.

Uno de los aspectos de interés que quiero destacar se refiere a las prácticas médicas experimentales con el fin de obtener una vacuna contra la sífilis. El desarrollo de los procedimientos de la vacuna antivariolosa llevó a pensar a algunos médicos en la posibilidad, mediante procedimientos similares, de obtener una vacuna para prevenir el mal venéreo. En este sentido, algunos médicos habían estado practicando con los pacientes de sífilis en hospitales en México; extraían líquido de los chancros y se inoculaba, tratando de inmunizar a la persona; lo único que lograban era el contagio. En estudios en Francia esta práctica clínica era común, ya que consideraban que los fluidos del chancro en el estadio secundario no contenían el "virus activo". En el Tratado práctico de la inoculación de las enfermedades venéreas de P. H. Ricord, médico francés experto en sífilis, se exponen todas las observaciones clínicas que influyeron para la reali-

115 HN, El Siglo Diez y Nueve, suplemento al número 472, D. F. (28 oct. 1868), pp. 2-3. La Gaceta Médica de México, núm. 12 del tomo III, f. 181. 
zación de estos experimentos. ${ }^{116}$ El doctor Juan Puerto, del Hospital de San Andrés, tenía gran inquietud por desarrollar una vacuna. Estuvo practicando la inoculación en varias personas no sifilíticas. Mostró los resultados al doctor Lavista, quien manifestó reservas ante un solo caso y aconsejó proseguir con los experimentos. Después de tener un número regular de hechos clínicos, éstos confirmarían o negarían la profilaxis. El doctor Puerto relata:

[Realicé] inoculaciones sifilíticas en dichos vacunados: testigos de ellas fueron varios practicantes del hospital de San Andrés, y en ninguno la sífilis prendía, no obstante transcurrir de 40 a 60 días; en vista de estos resultados, hablé al Sr. Dr. Juan J: R: de Arellano, especialista en Sífilis y uno de los primeros médicos en dicha especialidad; le mostré los casos; vacuné en su presencia, practicando después, inoculaciones sifilíticas [...]. Alentado por el éxito de los hechos verificados, invité al Sr. Mejía para que reconociese una persona con el objeto de que se viese que nunca había padecido la sífilis, con gusto accedió, y en presencia de los alumnos de Clínica interna de la cual es profesor, le practicó un reconocimiento cuyo resultado fue, el que dicha persona nunca había padecido la sífilis; inmediatamente la vacuné y dos días después el Sr. Mejía, tomó con una lanceta el virus sifilítico de una placa mucosa, le practicó dos inoculaciones en el brazo, pasaron más de 60 días y la sífilis no prendió. En vista de un éxito tan completo, publicó en "El Universal" una relación detallada del hecho clínico [...] manifestando que si la experiencia se verificaba siempre lo mismo y con éxito igual, la profilaxis de la sífilis sería una verdad. ${ }^{117}$

116 RicORD, Tratado práctico de la inoculación.

117 HN, La Medicina Científica (15 ene. 1894), D. F., pp. 24-26 [en versión digital 4]. 
El doctor Garay, alarmado ante estos hechos, pidió al Consejo de Salubridad detener esas prácticas experimentales y acusó al doctor Puerto de ser un ignorante en bacteriología y de que, en tal virtud, no podía ser cierta la profilaxis. El doctor Puerto estaba entusiasmado con su trabajo y deseaba presentar sus resultados en una reunión del Congreso de Higiene Americana que se efectuaría en México, por lo cual escribió al doctor Liceaga relatándole sus prácticas en una Memoria. ${ }^{118} \mathrm{~A}$ la luz de los conocimientos actuales sobre la sífilis y de la dificultad para crear una vacuna, el relato es impactante, pues la espiroqueta debió hacer estragos en muchas de las personas inoculadas en el Hospital de San Andrés, víctimas indefensas de estos terribles experimentos. Al parecer, los enfermos de sífilis fueron un grupo al que algunos médicos no tuvieron reparo en utilizar para sus investigaciones.

\section{A MANERA DE SÍNTESIS}

El eje articulador de los diversos apartados del trabajo, así como su secuencia, giran alrededor de identificar el carácter endémico de la sífilis, lo cual queda ampliamente demostrado, así como la presencia del padecimiento en diferentes sectores

118 Interesado en difundir sus experiencias contactó a médicos en Berlín, en particular al doctor Litten, quien le ofrecía su clínica para continuar sus investigaciones. Puerto llegó a Berlín y después de un ir y venir con algunos médicos alemanes, se puso en contacto con el doctor Lassar, especialista en la materia. Este médico le ofreció difundir los estudios entre sus estudiantes, pero para animarlos a someterse a esta práctica, el propio doctor Puerto debía ser inoculado frente a los alumnos, para no dejar duda de que era inofensiva. El desenlace de esta situación se desconoce. 
socioétnicos y en los diferentes grupos de edad. La información obtenida a partir de documentos de archivo correspondientes a periodos anteriores y posteriores es importante como referente y como consecuencia de la situación de la sífilis en el siglo xIx. De igual forma, la identificación de restos óseos con huellas de sífilis, de los siglos XVII al XIX, abona de manera positiva el planteamiento central. El análisis de los documentos de archivo, así como las evidencias osteopatológicas indican el carácter endémico de la sífilis, quizá desde el siglo xvi, diseminada por el territorio nacional a lo largo de los años. En la capital de México, fueron víctimas los jóvenes, cuya sexualidad los exponía a un mayor contagio. Se trataba de indios, mestizos y españoles; ningún sector escapó a la infección, cuyas características crónicas de larga duración, de expresión variable y no alarmante en su primera etapa, la hicieron más peligrosa. Las prostitutas, por la frecuencia de las relaciones y el tipo de comportamiento sexual, eran el sector más vulnerable y castigado; a ellas se les impuso control, condena, penas y multas, además de reclusión y secuestro, fueron llevadas a "prisión” y revisadas constantemente por parte de las autoridades sanitarias. Los soldados y sus acompañantes, las soldaderas, fueron otro sector de riesgo. Los niños adquirían la enfermedad en el vientre de sus madres infectadas, o en el nacimiento, o bien por contagio durante el amamantamiento de éstas, no por herencia, ya que no se trasmite vía genética. También por contagio de sus nodrizas y mediante la inoculación de la vacuna antivariólica procedente de niños enfermos sin diagnosticar. La condición más cruel de infección fue por medio de la inoculación por parte de los médicos del fluido tomado de chancros sifilíticos, tratando de experimentar para obtener una vacuna. 
Los relatos de doctores sobre los signos y síntomas de la sífilis demuestran el impacto corporal del mal, las expresiones de la infección, lo triste de la condición de los que padecían esta desagradable dolencia. Los tratamientos no podían ser más agresivos. La utilización de diversos compuestos a base de mercurio tenía efectos secundarios. La lectura de centenares de recetas donde se aplicaba este elemento lleva a la pregunta de si de algún modo había resultados positivos, ya que durante siglos se aplicaron ungüentos, inyecciones, se recetaron píldoras, se emplearon gases y todo tipo de tratamientos con mercurio.

No fue sino hasta los años cuarenta del siglo xx, con el advenimiento de la penicilina, cuando la enfermedad tuvo curación. Al respecto, menciono el caso del hospital de Alabama donde médicos realizaron un estudio clínico entre 1932 y 1972, conocido como Tuskegee, a un grupo de 408 afroamericanos, para observar la progresión de la sífilis si no era tratada, que ha sido objeto de varios estudios. La vacuna, aún ahora, ha sido imposible de producir. Para 1926 se consideraba el grupo de riesgo entre 14 y 26 años. En cuanto a la frecuencia del padecimiento José Almaraz dice: "En México puede asegurarse que el sesenta por ciento de la población padece de la infección específica: en la capital contamos con más de cincuenta por ciento de los habitantes sifilíticos”. De las mujeres públicas menciona: “[...] ejercen la prostitución que son cerca de veinte mil, dieciocho mil, se encuentran bajo la influencia del padecimiento específico; de la población comprendida entre los quince y los veinte años, el treinta por ciento padece de esta afección". ${ }^{119}$ Las

119 “Estudio que presenta el licenciado José Almaraz a la Comisión Revi- 
autoridades sanitarias consideraban indispensable continuar con medidas enérgicas para detener el contagio. Contemplaban la necesidad de educar a las masas populares en esta materia. ${ }^{120}$ En especial pedían establecer medidas profilácticas enérgicas y legislar para establecer en el Código Penal las medidas que castiguen a los que, con plena conciencia del mal, no tengan escrúpulo de ninguna especie en sembrar gérmenes nocivos. Podríamos pensar que la sífilis es una enfermedad del pasado, erradicada hace décadas; sin embargo, las cifras de reportes epidemiológicos muestran su permanencia en la actualidad en México. En el año 2000 se registraron 1824 casos anuales. De hecho, se detectó una prevalencia de $15.1 \%$ de T. pallidum. En sexoservidoras la tasa varía hasta $16.2 \%$. Las personas con mayor riesgo de contagio son los homosexuales jóvenes, las sexoservidoras, los migrantes, los usuarios de drogas intravenosas y la gente promiscua que vive en los barrios pobres de las grandes urbes. El surgimiento del síndrome de inmunodeficiencia adquirida (SIDA) ha recrudecido la situación al disminuir la capacidad inmunológica del individuo y las investigaciones han mostrado la presencia de la sífilis en porcentajes que ya no esperaríamos, a causa de la resistencia del agente causal a los antibióticos. ${ }^{121}$

sora del Código Penal, acerca de la creación de un nuevo delito: el de contagio (sexual y nutricio).” AHSP, Salubridad Pública, Servicio Jurídico, c. 5 [p. Guía 12], exp. 12 (1926-1927), f. 11.

120 Carrillo, "Control sexual”, p. 72.

121 Para el presente estudio conté con valiosas colaboraciones y apoyo de colegas y amigos a quienes expreso mi gratitud: Claudia Agostoni amablemente revisó un primer borrador del trabajo; sus indicaciones y aguda mirada me permitieron una adecuada reestructuración. Ana María Carrillo pacientemente dedicó largas horas a revisar, discutir y comentar este trabajo; sus sugerencias, reflexiones y amplio conocimiento del tema fueron 


\section{SIGLAS Y REFERENCIAS}

AGN Archivo General de la Nación, México.

AHSSA Archivo Histórico de la Secretaría de Salubridad y Asistencia, México.

AHDF Archivo Histórico del Distrito Federal, México.

ANM Academia Nacional de Medicina, México.

BMM Biblioteca del Museo de Medicina, México.

BP Beneficencia Pública, México.

HN Hemeroteca Nacional, México.

Aguilar Ochoa, Arturo

La fotografia durante el imperio de Maximiliano, México, Universidad Nacional Autónoma de México, 1996.

Alfaro, M.

"Sifilografía-. Ataxia locomotriz incipiente de naturaleza sifilítica. Heredo-sífilis”, en La Gaceta Médica de México, 26 (1891), pp. 488-496.

Aufdeheide, Arthur y Conrado Rodriguez-Martin

The Cambridge Encyclopedia of Human Paleopathology, Cambridge, Cambridge University Press, 1998.

fundamentales. Claudia Pardo y América Molina del Villar, con sus comentarios y sugerencias, contribuyeron a enriquecer el estudio y me estimularon para su publicación. Angélica Guerra participó de manera entusiasta y acuciosa en la búsqueda de la documentación en los archivos. A mis colegas Margarita Meza, Montserrat Méndez y Arturo Caballero, reconozco su entrega y dedicación en el análisis osteopatológico y en la revisión bibliográfica. En especial quiero agradecer a los dictaminadores anónimos cuyas detalladas observaciones, comentarios, sugerencias y críticas constructivas permitieron redefinir diversos aspectos y buscar aclararlos. La investigación fue apoyada por el proyecto Conacyt “Las epidemias y pandemias en México, siglos XVIII-XX (127712)", cuya responsable es América Molina del Villar y en el cual participo. Como es común en estas situaciones, reitero que la responsabilidad sobre lo aquí planteado es de mi exclusividad. 
Bailey, Francis J.

“Obituary. Philippe Ricord, M.D.”, en The British Medical Journal (1889), pp. 1070-1071.

Boldsen, Jesper L.

"Leprosy in the Early Medieval Lauchheim Community", en American Journal of Physical Anthropology, 135: 3 (mar. 2008), pp. 301-310.

Carrillo, Ana María

"Control sexual para el control social. La primera campaña contra la sífilis en México”, en Espacio Plural, xi: 22 (2010), pp. 65-77.

"Economía, política y salud pública en el México porfiriano (1876-1910)”, en História, Ciêcias, Saúde-Manguinhos 9, suplemento (2002), pp. 67-87.

Casillas, Tomás

"Tratamiento de las manifestaciones secundarias de la sífilis por inyecciones Subcutáneas de preparaciones mercuriales", BMM, ANM, unam, tesis Siglo xix, Clasificación S-T, 1876, HER, exp. 12.

Castillo, Oana del

"Condiciones de vida y salud de una muestra poblacional de la ciudad de México en la época colonial”, tesis de maestría en antropología física, México, Escuela Nacional de Antropología e Historia, 2000.

Cook, Della Collins y Mary Lucas Powell

"Treponematosis: Past, Present, and Future", en Anne L. Grauer (ed.), A Companion to Paleopathology, Oxford, Wiley, Blackwell, 2012, pp. 472-491.

Espinosa Solís, Erick Apolo

"Sexualidad y sífilis en la ciudad de México en el Virreinato: diagnóstico diferencial de enfermedad causada por treponema sp. en la colección ósea del Hospital Real de San José de los Na- 
turales (s. XVI-XVIII)", tesis de licenciatura en antropología física, México, Escuela Nacional de Antropología e Historia, 2006.

Estrada Urroz, Rosalina

"Control sanitario o control social: la reglamentación prostibularia en el Porfiriato", en Boletín Mexicano de Historia, 5: 2 (2002), pp. 21-25.

Fernández de Lara, Ignacio

"Tratamiento curativo de la sífilis", México, BMM, ANM, UNAM, tesis Siglo xIx, 1882, Clasificación S-T, 1870, HIG, exp. 5.

Florescano, Enrique y Elsa Malvido (eds.)

Ensayos sobre la historia de las epidemias en México, México, Instituto Mexicano del Seguro Social, Colección Salud y Seguridad Social, Serie Historia, 1982.

Gantús, Fausta

"La traza del poder político y la administración de la ciudad liberal (1867-1902)”, en Rodríguez Kuri (coord.), 2012, pp. 287-362.

Garza Velasco, Miguel de la

"Breves apuntes sobre la cauterización con el cauterio Paquelin”, BMM, ANM, Unam, tesis Siglo xix, Clasificación S-T. 1876-1880, CHI. exp. 10.

Gonzalbo Aizpuru, Pilar

Familia y orden colonial, México, El Colegio de México, 1998.

Наскет, C. J.

Diagnostic Criteria of Syphilis, Yaws, and Treponarid (Treponematoses) and of Some Other Diseases in Dry Bones (for Use in Osteo-Archaeology), Berlín, Springer-Verlag, 1976.

"On the origin of the human treponematoses (pinta, yaws, endemic syphilis, and venereal syphilis)", en Bulletin of the World Health Organization, 29 (1963), pp. 7-41. 
"An introduction to diagnostic criteria of syphilis, treponemarid and yaws (treponematoses) in dry bones, and some implications", en Virchows Arch. A. Path. Anat, and Histol, 368, pp. 229-241.

Harper, K. N., M. K. Zuckerman, M. L. Harper, J. D. Koingston, y G. J. Armelagos

"The Origin and Antiquity of Syphilis Revisited: An Appraisal of Old World Pre-Columbian Evidence”, en American Journal of Physical Anthropology, 54 (2011), pp. 99-133.

Hernández Franyuti, Regina (ed.)

La ciudad de México en la primera mitad del siglo XIX. Gobierno y política, sociedad y cultura, México, Instituto de Investigaciones Dr. José María Luis Mora, 1994.

Lugo, Concepción y Elsa Malvido

“Las epidemias en la ciudad de México, 1822-1850", en HerNÁndeZ Franyuti, 1994, vol. II, pp. 303-364.

Mansilla, Josefina

"A case of congenital syphilis during the Colonial period in México City", en American Journal of Physical Anthropology, 97 (1995), pp. 187-195.

Márquez Morfín, Lourdes

"Disease and Society in Colonial México: The skeletons of the National Cathedral”, en Paleopathology Newsletter, 32 (1980), pp. 6-8.

Sociedad colonial y enfermedad. Un ensayo de osteología diferencial, México, México, Instituto Nacional de Antropología e Historia, 1984.

“El cólera en México en 1833 y en 1991", en Estudios de Antropología Biológica, vi (1997), pp. 349-362.

La desigualdad ante la muerte en la Cindad de México. El tifo y el cólera, México, Siglo Veintiuno Editores, 1994. 
“Los parroquianos del Sagrario Metropolitano”, en MárqueZ Morfín y Gómez de León (eds.), 1998, pp. 95-125.

"Población y sociedad", en Rodríguez Pérez y Martínez Barbosa (eds.), 2001, pp. 13-22.

Márquez Morfín, Lourdes (ed.)

Los niños, actores sociales ignorados. Levantando el velo, Una mirada al pasado, México, Escuela Nacional de Antropología e Historia, Instituto Nacional de Antropología e Historia, Serie Investigación/Proa, Programa de Mejoramiento de Profesorado, Consejo Nacional para la Cultura y las Artes, 2010.

Márquez Morfín, Lourdes y José Gómez de León (eds.)

Perfiles demográficos de poblaciones antiguas de México, México, Instituto Nacional de Antropología e Historia, Consejo Nacional de Población, 1998.

Márquez Morfín, Lourdes y Margarita Meza Manzanilla

"La sífilis en la ciudad de México: análisis osteopatológico", en Cuicuilco [en prensa].

Martínez Barbosa, Xóchitl

“El Hospital de San Andrés”, en Viesca Treviño (ed.), 2001, pp. 435-439.

Miño Grijalva, Manuel

"La ciudad de México en el tránsito del virreinato a la república”, en Destiempos, 3(14) (2008), pp. 460-471.

Molina del Villar, América

La Nueva España y el Matlazabuatl, 1736-1739, México, Centro de Investigaciones y Estudios Superiores en Antropología Social, El Colegio de Michoacán, 2001.

Molina del Villar, América, Lourdes Márquez Morfín y Claudia Pardo Hernández (eds.)

El miedo a morir. Endemias, epidemias y pandemias en México: análisis de larga duración, México, Centro de Investiga- 
ciones y Estudios Superiores en Antropología Social, Instituto de Investigaciones Dr. José María Luis Mora, Benemérita Universidad de Puebla, Consejo Nacional de Ciencia y Tecnologías, 2013.

Moreno Toscano, Alejandra y Carlos Aguirre

"Migraciones hacia la ciudad de México durante el siglo xix: perspectivas de investigación”, en Investigaciones sobre la historia de la ciudad de México, Cuaderno de trabajo, I (1974), pp. 1-26.

Muriel, Josefina

Hospitales de la Nueva España, México, Universidad Nacional Autónoma de México, Cruz Roja Mexicana, 1990.

“Los hospitales en el siglo ilustrado", en Rodríguez Pérez y Martínez Barbosa (eds.), 2001, pp. 491-498.

Núñez Becerra, C. Fernanda

"El Juez. La prostituta y sus clientes: discursos y representaciones sobre las prostitutas y la prostitución en la ciudad de México durante el Imperio de Maximiliano (1864-1867)", tesis de maestria en historia, México, Escuela Nacional de Antropología e Historia, 1996.

Obregón, Diana

"Médicos, prostitución y enfermedades venéreas en Colombia (1886-1951)”, en História, Ciências, Saúde-Manguinhos, Río de Janeiro, vol. 9 (suplemento), 2002, pp. 161-186. www.scielo.br/pdf/hcsm/v9s0/07.pdf

Ortner, Donald y Walter Putschar

Identification of Paleopathological Conditions in Human Skeletal Remains, Washington, Smithsonian Institution Press, 1981.

Pérez Toledo, Sonia

"Formas de gobierno local, modelos constitucionales y cuerpo electoral, 1824-1867”, en Rodríguez Kuri (coord.), 2012, pp. 221-286. 
Pérez Toledo, Sonia y Herbert Klein

Población y estructura social de la ciudad de México, México, Universidad Autónoma Metropolitana, Conacyt, 2004.

Poincy Leal, Francisco de

"Estudio práctico sobre la sífilis infantil, hereditaria y adquirida”, BMM, ANM, UNAM, tesis Siglo xIx, Clasificación S-T, 1870, HIG. exp. 6.

"Algunos puntos dudosos de la sífilis", Biblioteca del Museo de Medicina, BMM, ANM, Unam, tesis Siglo xix, Calsificación: S-T, 1876-1880, CHI. exp. 10.

RICORD, P. H.

Tratado práctico de la inoculación, Barcelona, Don Juan Francisco Piforrer, Impresor de S. M. Plaza del Ángel, 1840.

Ríos DE LA TORRe, Guadalupe

"Mujeres públicas y burdeles en la segunda mitad del siglo xIx", en Historia, 4 (2004).

Rodríguez Cuenca, José Vicente

Las enfermedades en las condiciones de vida prehispánica de Colombia, Bogotá, Colombia, Universidad Nacional de Colombia, 2006.

Rodríguez Kuri, Ariel (coord.)

Historia política de la cindad de México. (Desde su fundación hasta el año 2000), México, El Colegio de México, 2012.

Rodríguez Pérez, Martha Eugenia y Xóchitl Martínez Barbosa (eds.) Medicina novohispana, siglo XVIII, en Historia General de la Medicina en México, vol. Iv, México, Universidad Nacional Autónoma de México, Academia Nacional de Medicina, 2001.

SAlLe, Víctor

"De la sífilis congénita y hereditaria”, México, BMM, ANM, unAm, tesis Siglo xix, Clasificación S-T, ROA, 1870, exp. 2. 
STeinbock, Ted R.

Paleopathological Diagnosis and Interpretation. Bone disease in ancient human population, Springfied, Charles C. Thomas Publisher, 1976.

VEGA, Librado

"Los accidentes secundarios y terciarios de la sífilis: ¿son contagios?”, BMM, ANM, unAM, tesis Siglo xix. Medicina y Cirujía, 1870.

Viesca Treviño, Carlos (ed.)

Medicina novobispana siglo XVIII, México, Academia Nacional de Medicina, Universidad Nacional Autónoma de México, 2001. 
